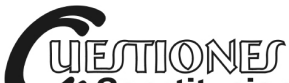

\section{PRICIPIO DE PROPORCIONALIDAD, COLISIÓN DE PRINCIPIOS Y EL NUEVO DISCURSO DE LA SUPREMA CORTE}

\section{PROPORTIONALITY ANALYSIS, CLASH OF PRINCIPLES, AND THE NEW DISCOURSE OF THE MEXICAN SUPREME COURT}

\author{
Rodrigo DíEZ GARGARI*
}

RESUMEN: En el contexto del neoconstitucionalismo, el uso del principio de proporcionalidad (el "PP") se ha convertido en la herramienta de adjudicación más dominante. Si bien el PP ha demostrado su utilidad debido, principalmente, a su flexibilidad y a su capacidad para incrementar la transparencia de las decisiones jurisdiccionales, también ha contribuido a generar una imagen de neutralidad que oscurece por el hecho de que los jueces, al resolver casos, toman decisiones políticas y no sólo aplican el derecho sino que también lo crean. El ejemplo de esta tensión se puede encontrar en diversos casos que la Suprema Corte de Justicia de la Nación (la "Corte") ha resuelto. Este trabajo busca analizar la manera en que la Corte utiliza el PP y sus implicaciones en nuestra vida constitucional.

Palabras clave: Principio de proporcionalidad, ponderación, tribunales constitucionales, principios y reglas.
ABSTRACT: In the context of New Constitutionalism, Proportionality Analysis (PA) has become the dominant adjudicative tool to solve modern day juridical problems. PA has proven to be a useful analytical tool especially because of its flexibility and its ability to increase the transparency of judicial decisions. Nevertheless, it has also generated an image of a neutral adjudicative method that clouds the fact that judges are engaging in substantial value as well as creating Law. An example of this situation can be found in some recent cases ruled by the Mexican Supreme Court (the "Court"). This paper analyzes how is it that the Court has used PA and its implications to Mexico's constitutional life.

Descriptors: Proportionality Analysis, balancing, constitutional tribunals, principles and rules.

*Abogado por la Escuela Libre de Derecho y maestro en Derecho constitucional por la Escuela de Derecho de la Universidad de Harvard; profesor titular de Teoría del derecho en la Escuela Libre de Derecho. 
If it be true that greater legal certainty is sought than is practically required or attainable, then the demand for excessive legal stability does not arise from practical needs. It must have its roots not in reality but in a yearning for something unreal.

Jerome FRANK

\section{EL PRINCIPIO DE PROPORCIONALIDAD: EN BUSCA DE LAS CERTEZAS PERDIDAS}

\section{Introducción}

El objetivo de este artículo es analizar el modo en que la Suprema Corte de Justicia de la Nación (la "Corte") ha usado el principio de proporcionalidad (el "PP"). ${ }^{1}$ Aunque este principio goza de una tradición más o menos larga en Europa (poco más de cincuenta años), en nuestro país es de muy reciente aplicación. De hecho, el primer caso en que la Corte lo utilizó se resolvió en 2004.

En tiempos recientes, el PP se ha convertido en la herramienta más utilizada por tribunales constitucionales en todo el mundo para resolver determinados conflictos jurídicos. Esto ha motivado la aparición, tanto en México como en otros países, de un buen número de obras que estudian este principio. ${ }^{2}$ A pesar de que es posible encontrar algunos trabajos

1 La Corte no mantiene un monopolio sobre el uso del PP. De entre los órganos jurisdiccionales que emiten jurisprudencia, tanto los tribunales colegiados de circuito como el Tribunal Electoral del Poder Judicial de la Federación (el "TEPJF") lo utilizan. Por razones de espacio, sin embargo, nos hemos limitado a analizar los casos resueltos por la Corte. En materia electoral se recomiendan los siguientes casos: SUP-RAP 50/2011; SUP-RAP 9/2004; SUP-JDC 393/2005, y SUP-RAP 31/2006.

2 En México destaca el libro de Rubén Sánchez Gil, El principio de proporcionalidad, México, UNAM, Instituto de Investigaciones Jurídicas, 2007. Por su amplia difusión en todo el mundo se recomienda, obviamente, Teoría de los derechos fundamentales, de Robert Alexy. También es muy recomendable Bernal Pulido, Carlos, El principio de proporcionalidad y los derechos fundamentales: el principio de proporcionalidad como 
de autores mexicanos sobre el PP, la mayoría de ellos se centra mucho más en el aspecto teórico y no en el análisis de las resoluciones judiciales en las que se aplica el principio. Los pocos trabajos sobre el análisis de decisiones judiciales le dedican un espacio menor que impide un análisis a fondo de los criterios utilizados por los órganos jurisdiccionales. ${ }^{3}$

Este trabajo tiene tres objetivos principales: a) presentar de manera clara la recepción del PP por parte de la Corte; $b$ ) mostrar el modo en que el principio ha permitido a la Corte elaborar un discurso para fortalecer su legitimidad y para aumentar su participación como un actor político protagónico ( $\sin$ necesidad de decirlo abiertamente, claro está), y c) evaluar los aspectos positivos y negativos del PP.

En la realización del presente trabajo he partido del supuesto de considerar a la Corte no sólo como un órgano técnico encargado de resolver conflictos entre determinadas partes sino como un actor político. En la medida en que la Corte actúa políticamente, es necesario considerar su actuación a partir de un "comportamiento estratégico" en el sentido de que, en la realización de sus actividades, procura promover sus propios intereses. Siguiendo las propuestas de Martin Shapiro, ${ }^{4}$ consideramos a las cortes como instituciones de decisión política, en las que el litigio funciona como el insumo (input) de la política y la resolución del caso como el resultado (output). De esta manera, las resoluciones de la Corte representan una forma de hacer política pues a partir de éstas "la Corte... legitima ciertas rutas políticas y deslegitima otras y le muestra al parlamento, a los jueces y a los futuros litigantes que ciertas líneas argumentativas se han restringido mientras que otras se han ampliado".

criterio para determinar el contenido de los derechos fundamentales vinculantes para el legislador, Madrid, CEPC, 2007.

3 De entre los autos que sí han analizado casos concretos destacan Rubén Sánchez Gil, "Recepción jurisprudencial del principio de proporcionalidad en México", Cuestiones Constitucionales, 21, 2009, (consulta 10 de febrero de 2011), formato html, disponible en http://www.juridicas.unam.mx/publica/rev/cconst/cont/21/cj/cj16.htm, y Conesa, Luisa, The Tropicalization of Proportionality Balancing: The Colombian and Mexican Examples), Cornell Law School Inter-University Graduate Students Conference Papers (consulta 10 de febrero de 2011), formato html, disponible en http://scholarship.law. cornell.edu/cgi/viewcontent.cgi? article $=1041 \&$ context $=l p s \_$clacp .

4 De este autor vale la pena consultar Law and Politics of the Supreme Court: New Approaches in Political Jurisprudence, Londres, Free Press, 1965 y Courts. A Comparative and Political Analysis, Chicago, The University of Chicago Press, 1992.

5 Stone Sweet, Alec, Governing with Judges, Oxford, Oxford University Press, 2000, p. 96. El original es [The Court...] legitimates some policy routes and delegitima- 
Lo anterior desde luego implica abandonar el punto de vista de que es posible llegar a una "única" respuesta correcta ${ }^{6}$ en la resolución de problemas jurídicos complicados pues, como ya se ha insistido, la Corte también busca sus propios intereses, y sus decisiones las toma con base en criterios políticos. Esto no quiere decir que los jueces en la práctica hagan lo que se les pegue su gana o que actúen en la arbitrariedad absoluta (al fin y al cabo su actividad política ocurre dentro de un contexto normativo y eso implica ciertas reglas del juego). ¿Qué busca —entonces- la Corte?: “Al resolver controversias, los jueces constitucionales pretenden preservar la superioridad normativa de la Constitución y asegurar que ésta se convierta (o continúe siendo) como el punto de referencia esencial para solucionar dichas controversias".?

2. ¿Para qué sirve el PP?

El PP funciona como un método para resolver controversias que implican la colisión de principios. ${ }^{8}$ Para comprender cabalmente lo anterior resulta útil contrastar dos pares de términos: los principios con las reglas y la ponderación con la subsunción. De conformidad con Robert Alexy, los principios son mandatos de optimización, esto es, “....normas que ordenan que algo sea realizado en la mayor medida posible, dentro de las posibilidades jurídicas y reales existentes". ${ }^{9}$ Por eso, los principios se caracterizan “...porque pueden cumplirse en diferente grado y [por]que la medida de-

tes others, and signals to parliament, the judiciary, and to future litigants that some lines of constitutional contestation have been closed off or narrowed, while others have been open up. La traducción es mía.

6 El término "única respuesta correcta" ha sido desarrollada de manera importante por Dworkin. Para un análisis crítico de la "única respuesta correcta", vale la pena consultar a Aulis Aarnio, "La tesis de la única respuesta correcta y el principio regulativo del razonamiento jurídico", Doxa: cuadernos de filosofía del derecho, 8, 1990, pp. 23-38.

7 Stone Sweet, Alec, op. cit., p. 141. El original es In resolving disputes, constitutional judges seek both to preserve the normative superiority of the constitutional law and to ensure that the constitution becomes, or continue to be, the essential reference point for the settlement of like cases that may arise in the future. La traducción es mía.

8 El PP también se usa en casos en los que hay que contrastar un principio con un interés gubernamental: clasificación, medida legislativa, etcétera. En este trabajo se usará la expresión "colisión de principios" para ambas situaciones.

9 Alexy, Robert, Teoría de los derechos fundamentales, Madrid, Centro de Estudios Políticos y Constitucionales, 2008, p. 67. 
bida de su cumplimiento no sólo depende de las posibilidades reales sino también de las jurídicas". ${ }^{10} \mathrm{El}$ caso paradigmático de los principios son los derechos fundamentales.

Las reglas, en cambio, son “....normas que sólo pueden ser cumplidas o no. Si una regla es válida, entonces debe hacerse exactamente lo que ella exige, ni más ni menos". ${ }^{11}$ La conclusión natural es que las reglas se aplican bajo un esquema de todo o nada mientras que los principios deben ser ponderados. Un ejemplo de regla es el artículo 302 del Código Penal Federal: "Comete el delito de homicidio: el que priva de la vida a otro". Para saber si resulta aplicable esta regla basta con utilizar el clásico silogismo, también conocido como método de la subsunción.

Con los principios, en cambio, ocurre algo muy distinto: cuando un principio choca con otro, el método de la subsunción no puede resolver dicho conflicto, justamente porque los principios no operan en un esquema de todo o nada. Habrá que acudir, entonces, a la ponderación. "Ponderar" no es otra cosa sino pesar un principio como si se pudiera colocar en el plato de una balanza. El PP implica esta ponderación. De hecho, siguiendo la terminología de Alexy, el tercer subprincipio del PP no es otra cosa sino el mandato de ponderación. ${ }^{12}$ "Cuanto mayor es el grado de la no satisfacción o de afectación de uno de los principios, tanto mayor debe ser la importancia de la satisfacción del otro". ${ }^{13}$

En esta época de neoconstitucionalismo en la que los derechos fundamentales funcionan como "mandatos de optimización" y en el que la colisión de derechos es un fenómeno cotidiano, el PP tiene la oportunidad de adquirir un protagonismo insólito porque nos brinda la esperanza de recuperar algo de la certeza y de la racionalidad que se ha perdido en esta época. ${ }^{14}$ En este sentido, el PP es muy reconfortante para la sensibilidad contemporánea.

Muchos de los que celebran el PP destacan que éste representa un límite efectivo para los jueces al obligarlos a proporcionar argumentos y a dar razones que fundamenten sus decisiones. En esa medida, los seguidores del

10 Ibidem, p. 68.

11 Idem.

12 Acerca de esto se abundará un poco más adelante.

13 Alexy, Robert, op. cit., p. 529.

14 Respecto a la crisis cultural, producto de la Ilustración y del Romanticismo, es indispensable consultar Berlin, Isaiah, "The Romantic Revolution: A Crisis in the History of Modern Thought", The Sense of Reality, Nueva York, Farrar, Straus and Giroux, 1998, pp.168-193. 
PP pretenden que éste les permite evitar la arbitrariedad o la subjetividad al momento de resolver casos jurídicos. "En esta búsqueda de racionalidad del derecho se implican las prohibiciones de arbitrariedad y de exceso en el ejercicio del poder público, íntimamente relacionadas con el PP...". ${ }^{15}$

A reserva de que un poco más adelante detallemos nuestra crítica metodológica y expliquemos nuestras reservas respecto de los presupuestos del PP, es necesario advertir desde este momento que cualquier beneficio que pueda brindar este principio sólo podrá ser alcanzado si los órganos jurisdiccionales aceptan de manera abierta sus implicaciones. Además del clásico argumento contra-mayoritario al que debe enfrentarse la revisión judicial, ahora las cortes enfrentan un nuevo reto: [La proporcionalidad] no oculta la creación judicial del derecho. Utilizada debidamente, requiere que las corte reconozcan y defiendan - honesta y abiertamente- las decisiones políticas que toman". ${ }^{16}$

\section{Los orígenes del PP: academia y jurisdicción}

To paraphrase Alexis de Tocqueville's observation regarding the United States,

there is now hardly any moral or political controversy in the world of new constitutionalism that does not sooner or later become a judicial one.

RAN HIRSCHL

La proporcionalidad tiene un doble origen, tanto doctrinal como judicial. En ambos casos nació en la misma tierra: Alemania. La experiencia alemana es relevante por dos razones. Primero, porque fue el primer país en usar este método para resolver la colisión entre principios. Segundo, porque la Ley Fundamental Alemana de 1949 (la "Ley Fundamental") y el

15 Sánchez Gil, Rubén, El principio de proporcionalidad, México, UNAM, Instituto de Investigaciones Jurídicas, 2007, p. 20.

16 Stone Sweet, Alec y Mathews, Jud, "Proportionality Balancing and Global Constitutionalism", Columbia Journal of Transnational Law, 47, 2008, p. 78 (consulta 10 de febrero de 2011), formato html, disponible en http://works.bepress.com/cgi/viewcontent. cgi ? article $=1010 \&$ context $=$ alec_stone_sweet. El original es PA [proportionality analysis] does not camouflage judicial lawmaking. Properly employed, it requires courts to acknowledge and defend - honestly and openly - the policy choices that they make when they make constitutional choices. La traducción es mía. 
diseño del Tribunal Constitucional Alemán han influido a un sinnúmero de países, incluido México.

Si bien Robert Alexy, no fue el primer jurista en referirse a la proporcionalidad (de hecho los orígenes doctrinarios pueden rastrearse hasta el siglo XVIII), ${ }^{17}$ debido a su importancia y a que su obra Teoría de los derechos fundamentales es un referente obligatorio sobre el tema, nos basaremos en sus trabajos para detallar cómo funciona el PP. Según el autor alemán, el PP tiene tres subprincipios que funcionan como los pasos de un examen para analizar una colisión de principios o una colisión entre un principio y un interés estatal legítimo: idoneidad, necesidad y proporcionalidad en sentido estricto (o ponderación). Para ejemplificar cómo funciona cada uno de los subprincipios es posible tomar como punto de partida una norma legal que afecte a un derecho fundamental. Dicha medida legislativa será idónea cuando sirva para promover el principio u objetivo que se busca satisfacer. Así, el legislador sólo puede afectar un determinado principio cuando la medida promueva a su vez otro principio. De acuerdo con Alexy, este subprincipio: “...no es otra cosa sino la expresión de la eficiencia de Pareto: una posición puede ser mejorada sin perjudicar otra" ${ }^{18}$ El principio de "necesidad" es parecido a lo que la Corte Suprema estadounidense llama least restrictive means, ${ }^{19}$ y consiste en que, si existen diversas opciones para satisfacer un principio, se debe elegir la que afecte en la menor medida al otro principio. El tercer subprincipio es lo que Alexy llama la "ley de la ponderación" o proporcionalidad en sentido estricto y funciona de manera similar a una balanza en el sentido de que a mayor peso de un lado, mayor afectación del otro: "Cuanto mayor es el grado de la no satisfacción o de afectación de uno de los principios, tanto mayor debe ser la importancia de la satisfacción del otro". ${ }^{20}$ Dada la caracterización de los principios de Alexy como

17 Para un buen recuento histórico de los orígenes doctrinales y judiciales del PP en Alemania vale la pena consultar idem.

18 Alexy, Robert, "Constitutional Rights, Balancing and Rationality", Ratio Iuris, 16, 2003, p. 135. El original es ... is nothing else than an expression of the idea of Pareto optimality: One position can be improved without detriment to another. La traducción es mía.

19 El estándar de least restrictive means es un examen que utiliza la Corte norteamericana para analizar legislación que afecta derechos constitucionales. De acuerdo con este estándar, bajo ciertas condiciones es posible expedir una ley que afecte un derecho fundamental, siempre y cuando dicha ley utilice los medios menos restrictivos del derecho para cumplir con su finalidad.

20 Alexy, Robert, op. cit. 
mandatos de optimización, la única manera de aplicarlos sin destruirlos es recurriendo al PP. Siguiendo lo dicho por Alexy, es posible afirmar que dado que los principios no se aplican en un esquema de todo o nada, es indispensable una herramienta lo suficientemente flexible para captar su "verdadera naturaleza". ${ }^{21}$

En este punto es indispensable distinguir entre la ponderación en un sentido ordinario y la ponderación como uno de los subprincipios del PP. El segundo es la ley de la ponderación de Alexy; el primero, en cambio, es un método interpretativo "basado en la identificación, evaluación y comparación de intereses que compiten entre sí". ${ }^{22}$ Este método de interpretación bien podría ser calificado como un rudimentario análisis de costo beneficio y, en esa medida, es algo que los jueces vienen haciendo desde hace ya mucho tiempo.

Acerca de los orígenes judiciales del PP se debe advertir que dicho principio no está reconocido en la Ley Fundamental. En realidad, este principio fue retomado por el Tribunal Constitucional principalmente de los trabajos de diversos académicos.

Inicialmente invocó [el Tribunal Constitucional] elementos de la proporcionalidad caso por caso, sin dar ninguna referencia de autoridad y sin explicar las razones para su aplicación. Al día de hoy, la corte no ha explicado los orígenes de la proporcionalidad. Como dice Dieter Grimm (Ministro del Tribunal Constitucional, 1987-99): "El principio se empezó usar como si se hubiera dado por hecho" ...Para finales de la década de los cincuenta, el Tribunal ya había elaborado el ya famosos examen de proporcionalidad con sus distintas etapas. ${ }^{23}$

21 Creo que no es aventurado decir que Alexy sí cree en la capacidad para conocer las esencias de las cosas. Esto se desprende de sus afirmaciones en el sentido de que el objetivo más importante de la filosofía del derecho es la naturaleza del derecho y de que esto implica poner atención a reflexiones sobre la ontología, la moral y la epistemología. Sobre el particular vale la pena consultar Alexy, Robert, "The Nature of Legal Philosophy", Ratio Iuris, 17, 2004, pp. 156-167 (consulta 10 de febrero de 2011), formato html, disponible en http://idv.sinica.edu.tw/philaw/Jurisprudence_Reading/The\%20Nature\%20of\%20Legal\%20Philosophy.pdf.

22 Aleinikoff, Alexander, "Constitutional Law in the Age of Balancing", Yale Law Journal, 96 (1986-1987), p. 945. El original es “...based on the identification, valuation, and comparison of competing interests". La traducción es mía.

23 Stone Sweet, Alec, op. cit., p. 108. El original es "It initially invoked [the German Court] elements of proportionality on a case-by-case basis, without citing authority or giving a rationale for its application. To this day, the court has not explicated the source of proportionality. As Dieter Grimm (Justice of the GFCC, 1987-99) puts it: 'The principle 
Uno de los casos más famosos y representativos del Tribunal Constitucional Alemán (pues en él ya se pueden distinguir los subprincipios) es el de Apothekenurteil (1958). ${ }^{24}$ En este caso se combatió la constitucionalidad de una ley bávara que regulaba a las farmacias, por estimar que ésta violaba el derecho a la libre ocupación previsto en el artículo 12, párrafo primero de la Ley Fundamental. Para resolver el caso, la Corte Constitucional partió de la colisión entre el derecho individual de libertad ocupacional y los objetivos públicos: "The [purpose of] constitutional right should be to protect the freedom of the individual [while the purpose of] the regulation should be to ensure sufficient protection of societal interests". ${ }^{25}$ De Alemania, este principio ha viajado a un sinnúmero de lugares en los que ha encontrado carta de naturalización, como en el caso de México.

4. La proporcionalidad y la fórmula del peso: ¿un método racional y objetivo?

Go, go, go, said the bird: human kind cannot bear very much reality

T. S. ELIOT

Antes de continuar quisiera profundizar un poco en las que a mí me parecen deficiencias metodológicas del PP. Este trabajo no es ni un lamento sobre la popularidad que ha adquirido el principio ni un intento por eliminarlo de la práctica jurisdiccional. Tampoco pretende ser una crítica extensa al PP o a sus presupuestos lógicos y filosóficos. Sobre el particular hay un buen número de autores que han llevado a cabo críticas muy puntuales. ${ }^{26}$

was introduced as if it could be taken for granted'... By the close of the 1950's, the GFCC had elaborated the familiar multi-stage framework". La traducción es mía.

24 Para un buen extracto traducido al español, vale la pena consultar Schwabe, Jürgen (comp.), Jurisprudencia del Tribunal Constitucional Federal Alemán (extractos de las sentencias más relevantes compiladas por Jürgen Schwabe), trad. Marcela Anzala Gil y Emilio Maus Ratz, México, Konrad Adenauer Stiftung, 2009.

25 Stone Sweet, Alec, op. cit., p. 108.

26 Me parece especialmente certera la crítica de Ricardo Guibourg en "Alexy y su fórmula del peso”, en Beada, Gustavo y Clérico, Laura (eds.), Desafios a la ponderación, 
Sin embargo, es necesario hacer dicha crítica (así sea menor) para que el lector pueda advertir con toda claridad desde qué posición se ha realizado el presente trabajo.

Ya se ha dicho que, para Alexy, el tercer subprincipio del PP no es otra cosa sino el mandato de ponderación. El problema es que si nos quedamos ahí no es posible avanzar gran cosa. ¿Cómo se deben pesar los principios? ¿Los principios tienen un valor o debemos asignárselos nosotros? Alexy pretende resolver estos problemas mediante su "fórmula del peso", que en palabras del propio autor "...complementa la ley de colisión y la ley de ponderación". 27

Esta fórmula es en realidad una fórmula "matemática" que nos permite saber cuál principio debe pesar más en un caso concreto justamente cuando ocurre una colisión entre principios. ${ }^{28}$ No pretendo explicar el funcionamiento de la fórmula porque ocuparía demasiado espacio y porque la explicación del propio Alexy es muy clara. Lo relevante es la idea de Alexy sobre la posibilidad de determinar cuál principio debe prevalecer sobre otro en una situación concreta, a partir de la asignación de distintos valores. Todo lo anterior suena más que aceptable y hasta deseable. ¿Qué objeción se podría hacer? Que lo dicho por el jurista alemán descansa sobre un presupuesto que nunca demuestra. Tanto el PP como la fórmula del peso pretenden ser una “...demostración de que es posible aplicar racionalmente los principios". ${ }^{29}$ Sin embargo, dicha demostración resulta imposible si no aceptamos como presupuesto algún tipo de objetivismo moral. Ciertamente, el propio Alexy trata de combatir avant la lettre este argumento y ha dicho lo siguiente:

Bogotá, Universidad Externado de Colombia, 2011. Sobre la discusión más amplia dentro de la cual se lleva a cabo la crítica al PP (relaciones derecho/moral), vale la pena consultar Alexy, Robert y Bulygin, Eugenio, La pretensión de corrección del derecho: la polémica Alexy/Bulygin sobre la relación entre derecho y moral, Bogotá, Universidad Externado de Colombia, 2001.

27 Alexy, Robert, op. cit., p. 539.

28 Para una buena introducción a la fórmula del peso, además de los propios libros de Alexy, vale la pena consultar a Bernal, Carlos, "La ponderación como procedimiento para interpretar los derechos fundamentales”, en Cáceres, E. et al. (eds.), Problemas contemporáneos de la filosofía del derecho, México, UNAM, 2005 (consulta 10 de febrero de 2011), formato html, disponible en http://www.bibliojuridica.org/libros/4/1650/5.pdf.

29 Guibourg, Ricardo, “Alexy y su fórmula del peso", en Beada, Gustavo y Clérico, Laura (eds.), Desafios a la ponderación, Bogotá, Universidad Externado de Colombia, 2011. No se cita el número de página porque el autor me proporcionó el manuscrito antes de que se publicara el libro. El original no lo tuve a la mano. 
La objetividad en el derecho no significa verificabilidad (provability), como en las matemáticas o en las ciencias naturales. La objetividad es la contracara de la arbitrariedad. ... Sin embargo, pertenece a la naturaleza de la argumentación legal que tengamos elementos de razón, argumentos racionales, en algún punto intermedio entre la verificabilidad y la arbitrariedad. ...Si en un caso tenemos buenos argumentos para un lado y para otro, y el tribunal se decide por uno de los dos con buenos argumentos, entonces la decisión habrá sido tomada con objetividad, en el sentido de razonabilidad que he tratado de explicar. ${ }^{30}$

Por la contundencia de la crítica vale la pena citar textualmente a Ricardo Guibourg:

Si hay buenos argumentos a favor y en contra de una misma solución, y si un tribunal decide sobre la base de esos argumentos, y si esta decisión es objetiva, esto significa que uno de los conjuntos de argumentos fue mejor que el otro (con lo que el otro conjunto de argumentos no era realmente bueno), o que la decisión no es objetiva sino subjetiva. ${ }^{31}$

Si bien pienso que el PP no es una muy buena guía como demostración de la posibilidad de aplicar racionalmente los principios, usado de cierta manera el PP puede resultar útil. Esto porque se trata de una estructura metodológica que puede servir para hacer explícitas las razones por las que un tribunal toma una decisión, es decir, para argumentar de manera abierta el porqué de una resolución. Además, por su flexibilidad “...tanto para proteger los derechos fundamentales como para mantener al propio derecho constitucional como un límite efectivo frente al poder a lo largo del tiempo". ${ }^{32}$

Sin embargo, la única manera de obtener estos beneficios es si los órganos jurisdiccionales aceptan abiertamente las implicaciones del PP. De lo contrario, podemos toparnos con lo que Vicki Jackson denomina "el lado oscuro de la proporcionalidad". "Debido a que corresponde y a que sirve para estructurar nociones intuitivas de justicia y reacciones pragmáticas frente a situaciones de hecho, es una aproximación que establece límites

30 "Sobre reglas y principios", entrevista a Robert Alexy, en La Ley Actualidad, Buenos Aires, 30 de octubre de 2008, p. 1, citado en idem.

31 Guibourg, Ricardo, op. cit.

32 Jackson, Vicki, "Being proportional about proportionality", Constitutional Comments 21, 2004, p. 829. El original es "both for protecting rights and maintaining constitutional law as an effective legal constraint on government over time". La traducción es mía. 
menos rígidos a los órganos de poder justamente en momentos en los que puede haber mayor tentación para alejarse de los mecanismos tradicionales de protección de las libertades". ${ }^{33}$ Para obtener cualquier beneficio del PP es necesario cumplir ciertas condiciones.

En primer lugar, los órganos jurisdiccionales deben aceptar abiertamente que el PP no garantiza la aplicación racional de los principios pues se trata tan sólo de un método para transparentar la evaluación de dos valores u opiniones. Además, los jueces deben abandonar esa visión ingenua consistente en que al usar este principio no están creando derecho. Por último, deberán aceptar que la utilización del PP no garantiza la neutralidad de la decisión, esto es, no elimina la posibilidad incorporar valoraciones o criterios morales propios al momento de interpretar y de aplicar la ley.

Utilizar el PP como si fuera un método capaz de garantizar la racionalidad de la aplicación de principios, como una herramienta que sólo se limita a "encontrar" los principios que ya estaban ahi ${ }^{34}$ y como un método capaz de garantizar la absoluta neutralidad en la aplicación de la ley, se traduce en un obstáculo para la discusión pública de las resoluciones judiciales que impide la construcción de lo que Guibourg llama soluciones consensuadas: "Es imposible encontrar una solución correcta en un sentido objetivo y susceptible de prueba; pero es posible (aunque difícil) construir soluciones consensuadas que puedan ser calificadas intersubjetivamente como aceptables". ${ }^{35}$ Por el contrario, de seguir viendo el PP como un método que elimina la subjetividad del juez, corremos el riesgo de no llegar a esas soluciones.

Siguiendo las ideas de Stone Sweet, se puede decir que, en su actividad ordinaria, los tribunales constitucionales pretenden establecer a la Constitución como el mayor punto de referencia para solucionar conflictos. Para ello, se valen de distintas estrategias como presentar sus decisiones como si fueran completamente distintas de los procesos "políticos". Otra de estas estrategias consiste en crear una imagen de su labor como si fuera un puro ejercicio lógico capaz de garantizar una supuesta neutralidad. Como dice

33 Ibidem, p. 856. El original es "Because it corresponds to and helps structure intuitive notions of fairness and pragmatic reactions to factual situations, it is an approach that may offer less constraint on political branches at those times when they are most tempted to depart from customary protections of liberties -for at those times courts will be so tempted as well”. La traducción es mía.

34 Desde luego, esta sería la posición de autores como Ronald Dworkin, un devoto de los principios subyacentes en el orden jurídico.

35 Guibourg, Ricardo, op. cit. 
Stone Sweet: "Esta lógica se expresa en última instancia como un silogismo: la constitución, como norma superior dispone X; el acto que se ataca por inconstitucional puede cumplir o no con X; en la medida que no cumple con X, es nulo o inconstitucional". ${ }^{36}$ A estas alturas resulta obvio que el PP es una herramienta muy útil para poner en práctica estas estrategias.

Desde mi punto de vista, es necesario combatir la opacidad que generan estas estrategias, especialmente porque ocultar lo que en realidad está haciendo un tribunal constitucional obstaculiza de manera grave la discusión pública de las resoluciones judiciales. Como estos tribunales suelen ser la última instancia en los mecanismos de defensa de la Constitución, la única manera de controlarlos y para exigirles cuentas es mediante la discusión. Sin embargo, para poder discutir es indispensable saber qué se está discutiendo.

\section{EL CASO MEXICANO: LA PROPORCIONALIDAD \\ LLEGA AL NUEVO MUNDO}

Durante la mayor parte del siglo XX, la Corte estuvo relegada a una función de espectador en la toma de decisiones políticas. Actualmente, como consecuencia de las reformas constitucionales de 1994, se ha convertido en uno de los actores políticos más activos y más importantes. ${ }^{37}$ La Corte ha sido especialmente exitosa en esto debido a que ha sido capaz de crear una imagen de árbitro neutral frente a la aparente corrupción y superficialidad de los arreglos políticos

Las nuevas facultades de la Corte (acciones de inconstitucionalidad y las renovadas controversias constitucionales) han desempeñado un papel

36 Stone Sweet, Alec, op. cit., p. 142. El original es "The logic is ultimately expressed as a syllogism: the constitution, as higher law, requires X; the act which has been attacked as unconstitutional falls either within or outside category $\mathrm{X}$; to the extent that said act falls outside of category $\mathrm{X}$, it is void as unconstitutional". La traducción es mía.

37 Cuando hablo de "decisiones políticas" o de "asuntos políticos" me refiero a lo que en inglés se conoce como policy questions o policy choices. La traducción de estos términos es muy complicada porque las expresiones "argumentos de conveniencia", de "utilidad", "políticos", etcétera, no captan completamente su sentido. Me parece que una buena explicación del alcance de estos términos se puede encontrar en la traducción del texto "La educación legal como preparación para la jerarquía" que hicieron María Luisa Piqué y Christian Courtis, en Desde otra mirada, Buenos Aires, Eudeba, 2000: "el término se refiere a los argumentos que explican la conveniencia de una decisión a partir de la ponderación de su resultado en referencia a un objetivo social, político, económico o moral que se considera deseable". 
importante en la fuerza que ha adquirido como actor político; sin embargo, existen otros factores extra-constitucionales que han contribuido a fortalecer este nuevo rol. Me refiero a la falta de legitimidad del Ejecutivo y del Legislativo (situación que ha aprovechado muy bien la Corte) ${ }^{38}$ así como al nuevo discurso de "autorepresentación como tribunal constitucional", mecanismo a partir del cual la Corte ha logrado aumentar de manera notable su poder. Quien mejor ha tratado este tema de la autorepresentación es sin duda el ahora ministro José Ramón Cossío. Antes de llegar a la Corte, el ministro sostuvo que "... es precisamente el embrujo de la noción de tribunal constitucional lo que ha sido el criterio base para la ordenación de los preceptos constitucionales y, lo que es más importante, el elemento determinante para la resolución de las decisiones difíciles a las que ha debido enfrentarse". ${ }^{39}$ Ampliando sobre esto, el ministro insiste sobre lo siguiente: "Esta noción posibilita (y, por lo mismo, es una de sus funciones) lo que bien podríamos llamar un decisionismo judicial, es decir, la posibilidad de llegar a cualquier tipo de construcción constitucional a partir de la idea de que se tiene la calidad para hacerlo". ${ }^{40}$ Esto que el ministro Cossío decía sobre la autorepresentación de la Corte como un tribunal constitucional bien puede decirse del PP, pues también es un mecanismo mediante el cual la Corte puede ampliar sus competencias "tan lejos como sea necesario".

\section{LA CORTE Y EL PP: OCHO CASOS REPRESENTATIVOS}

I reject the law/politics distinction on empirical grounds. The decision-making

behaviours that constitutional review engenders are always both judicial and

political.

Alec Stone SweEt

38 En tiempos recientes, la gente tiene más confianza en la Corte que en el presidente o que en los diputados o senadores. Para un estudio sobre la confianza en instituciones vale la pena consultar el Monitor MensUal de Consulta Mitofsky (Gobierno y Política) (consulta 22 de febrero de 2011), formato html, disponible en http://www.consulta.mx/ Docs/FusionCharts/EPG_Ene.pdf.

39 Cossío, José Ramón, La teoría constitucional de la Suprema Corte de Justicia, México, Fontamara, 2002, p. 173.

40 Ibidem, p. 174. 
Para analizar la manera en que la Corte ha usado el PP he seleccionado ocho casos representativos. Como el PP es una herramienta propia de tribunales constitucionales, hemos limitado este trabajo sólo a los casos surgidos después de las reformas de 1994. El criterio utilizado fue tomar en cuenta tesis aisladas o de jurisprudencia en las que se mencione de manera explícita los términos "proporcionalidad" y/o "ponderación". Esta metodología puede dejar de lado algunos casos en los que el PP sí se usa aunque no se le mencione de manera explícita en las tesis; ${ }^{41}$ sin embargo, la selección nos parece lo suficientemente representativa. En cada uno de ellos se contestarán las siguientes preguntas:

i) ¿El órgano jurisdiccional usó el PP con rigor (tomando como parámetro a los tres subprincipios mencionados por Alexy)?

ii) ¿Existe una justificación para usar el PP en el presente caso? ¿Fue útil? ¿La utilización del PP aporta algo que no se hubiera podido hacer con otro método?

iii) ¿El órgano jurisdiccional acepta de manera abierta las implicaciones de usar el PP?

\section{Amparo en revisión 988/2004: el origen ${ }^{42}$}

ElPP se usó por primera vez en México en el amparo en revisión 988/2004, resuelto por la Primera Sala de la Suprema Corte de Justicia el 29 de septiembre de 2004. En este asunto, el quejoso planteó la inconstitucionalidad de los artículos 70 y 90 del Código Penal Federal debido a que permitían el otorgamiento de la libertad bajo caución tomando como parámetro el

41 Por ejemplo, estamos dejando fuera a la acción de inconstitucionalidad 60/2009 y su acumulada 61/2009. En ese caso, un partido político (el PAN) combatió mediante una acción de inconstitucionalidad la eliminación de la figura de la candidatura común en el estado de Guanajuato. La Corte concluyó que la eliminación de esa figura por el legislador local era constitucional. Derivada de dichas acciones, surgió una tesis de jurisprudencia en la que se dice que el legislador tendrá facultades para regular las formas asociativas que pueden usar los partidos políticos, con la condición de que dicha regulación no sea arbitraria, innecesaria, desproporcionada o incumpla con criterios de razonabilidad. Como se puede ver claramente, en este asunto la Corte usó el PP. Sin embargo, por la razón mencionada, tuvimos que dejarla de lado. Además, por su relevancia (especialmente por su repercusión en la acción de inconstitucionalidad 26/2010 que recientemente se promovió en contra de la llamada "Reforma Peña"), el análisis de este asunto ameritaría un artículo separado.

42 El ministro ponente fue José Ramón Cossío; la secretaria fue Rosalba Rodríguez; el amparo se resolvió por unanimidad de cuatro votos. 
número de años fijados en la condena en lugar de atender a la diferencia entre delito grave y delito no grave. Según él, el hecho de que la libertad se otorgara con base en la duración de la condena y no en la gravedad del delito, violaba su derecho a la igualdad. Este amparo en revisión es uno de los precedentes que participó en la formación de las tesis de jurisprudencia rubros: a) IGUALDAD. CRITERIOS PARA DETERMINAR SI EL LEGISLADOR RESPETA ESE PRINCIPIO CONSTITUCIONAL, Y B) IGUALDAD. CASOS EN LOS QUE EL JUEZ CONSTITUCIONAL DEBE HACER UN ESCRUTINIO ESTRICTO DE LAS CLASIFICACIONES LEGISLATIVAS (INTERPRETACIÓN DEL ARTÍCULO 10. DE LA CONSTITUCiÓn Política de los Estados Unidos MeXicANos).

Es importante no confundir el PP con la ponderación en un sentido ordinario, es decir, "ponderación" no como uno de los subprincipios del PP sino como una comparación entre distintos intereses que compiten entre sí. La ponderación en este sentido ordinario es algo que los órganos jurisdiccionales hacen desde hace mucho tiempo aunque no utilicen este término en particular, y bajo ningún motivo puede ser calificada como una actividad reciente. El PP, en cambio, sí es una novedad, como también lo es la ponderación entendida como el subprincipio del PP, es decir, como la ley de la ponderación identificada por Alexy.

En este amparo se utilizó el PP en un sentido muy similar al usado por el Tribunal Constitucional Alemán; sin embargo, también se incorporaron algunos ingredientes propios de los distintos tipos de escrutinio que usa la Corte Suprema de los Estados Unidos para analizar casos de igualdad..$^{43} \mathrm{Si}$ guiendo de cerca lo fijado por el Tribunal Constitucional Alemán, la Primera

43 La Corte Suprema de los Estados Unidos utiliza distintos tipos de escrutinio para resolver conflictos relacionados con la cláusula de equal protection prevista en la décimo cuarta enmienda. El escrutinio estricto se usa para resolver casos en los que se hace una clasificación a partir de criterios "sospechosos" como la raza; el escrutinio ordinario se usa en casos en los que el legislador tiene una amplia libertad para establecer clasificaciones, como es el caso de asuntos "económicos"; el escrutinio ordinario se coloca entre los dos anteriores y se ha utilizado, por ejemplo, para tratar con clasificaciones que no sean de las "sospechosas" pero sobre las cuales el legislador no tiene un amplio poder de decisión, por ejemplo, clasificaciones con base en el sexo de las personas. Para una exposición clara al respecto vale la pena consultar el capítulo V de Stone, Tushnet et al., Constitutonal Law, Nueva York, Wolters Klower, 2009. Los distintos tipos de escrutinio aparecieron por primera vez en la ya famosa nota al pie 4 del célebre caso United States $v$. Carolene Products, elaborada por el ministro Stone. Para una introducción al caso Carolene Products se puede ver Ackerman, Bruce, "Beyond Carolene Products", Harvad Law Review, 98, 1985, pp. 713-746 y Lusky, Louis, "Footnote 4 Redux: A Carolene Products Reminiscence”, Columbia Law Review, 82, 1982, pp. 1093-1109. 
Sala de la Corte identificó ciertos sub-principios del PP: $a$ ) finalidad objetiva y constitucionalmente válida; b) racionalidad o adecuación de la distinción hecha por el legislador: "es necesario que la introducción de una distinción constituya un medio apto para conducir al fin u objetivo que el legislador quiere alcanzar, es decir, que exista una relación de instrumentalidad entre la medida clasificatoria y el fin pretendido", ${ }^{44}$ y c) proporcionalidad:

el legislador no puede tratar de alcanzar objetivos constitucionalmente legítimos de un modo abiertamente desproporcional, de manera que el juzgador debe determinar si la distinción legislativa se encuentra dentro del abanico de tratamientos que pueden considerarse proporcionales, habida cuenta de la situación de hecho la finalidad de la ley y los bienes y derechos constitucionales. ${ }^{45}$

A pesar de las similitudes con el Tribunal Alemán, se puede observar que la Primera Sala no habla del subprincipio de "necesidad", y se refiere únicamente a los de "idoneidad" (al que designa como de "racionalidad" o de "adecuación") y de "proporcionalidad". Siguiendo el modelo norteamericano (que utiliza distintos tipos de escrutinio dependiendo del derecho involucrado), la Primera Sala estableció que cuando una distinción afecte a derechos fundamentales o se refiera a una clasificación de las consideradas "sospechosas" por la propia Corte (origen étnico o nacional, edad, discapacidades, condición social, condiciones de salud, religión, preferencias, estado civil o cualquier otra que menoscabe la dignidad humana) aplicará un escrutinio estricto; cuando no los afecte, aplicará un escrutinio ordinario. Los subprincipios del examen alemán se modularán dependiendo del tipo de escrutinio. Esta combinación de los criterios norteamericano y alemán puede ser representado gráficamente de la siguiente manera:

\begin{tabular}{|l|l|l|}
\hline \multicolumn{1}{|c|}{ Subprincipios } & \multicolumn{1}{|c|}{ Escrutinio estricto } & \multicolumn{1}{c|}{ Escrutinio ordinario } \\
\hline $\begin{array}{l}\text { Finalidad objetiva y constitucio- } \\
\text { nalmente válida }\end{array}$ & $\begin{array}{l}\text { Deberá tratarse de un "objetivo } \\
\text { constitucionalmente importan- } \\
\text { te". }{ }^{66}\end{array}$ & $\begin{array}{l}\text { Basta con una finalidad consti- } \\
\text { tucionalmente admisible, “...esto } \\
\text { es, una finalidad no abiertamente } \\
\text { contradictoria con las disposicio- } \\
\text { nes constitucionales....". }{ }^{77}\end{array}$ \\
\hline
\end{tabular}

${ }^{44}$ Ejecutoria de amparoen revisión 988/2004 (consulta 10 de febrero de 2011), disponible en http://www2.scjn.gob.mx/ius2006/UnaEj.asp?nEjecutoria $=19685 \& T p o=2$.

${ }^{45}$ Idem.

46 Idem.

47 Idem. 


\begin{tabular}{|c|c|c|}
\hline Adecuación & $\begin{array}{l}\text { La medida lesgislativa deberá } \\
\text { estar “...directamente conecta- } \\
\text { da con la consecución de los } \\
\text { objetivos constitucionales...". }\end{array}$ & $\begin{array}{l}\text { Será suficiente con que la medida } \\
\text { esté "...potencialmente conecta- } \\
\text { da con la consecución de tales } \\
\text { objetivos". }{ }^{49}\end{array}$ \\
\hline $\begin{array}{l}\text { Proporcionalidad en sentido } \\
\text { estricto }\end{array}$ & $\begin{array}{l}\text { Será necesario que "...la dife- } \\
\text { rencia de trato refleje un balance } \\
\text { cuidadoso de las distintas exi- } \\
\text { gencias normativas en juego, y } \\
\text { que no se detecten alternativas } \\
\text { menos gravosas para los derechos } \\
\text { capaces de conducir a ese fin". }{ }^{50}\end{array}$ & $\begin{array}{l}\text { "...basta que no exista un desba- } \\
\text { lance grosero entre el objetivo al } \\
\text { servicio del cual está la medida } \\
\text { clasificadora". }{ }^{51}\end{array}$ \\
\hline
\end{tabular}

De inmediato llama la atención cierta confusión terminológica. Lo que la Corte designa como el subprincipio de "proporcionalidad" es en realidad el de "necesidad (siguiendo a Alexy). Esto es así porque el análisis de las "alternativas menos gravosas" se lleva a cabo en la etapa de "necesidad", no en la de "proporcionalidad". Para apoyar lo anterior vale recordar las palabras del propio Alexy: "Este subprincipio exige que de dos medios igualmente idóneos, sea escogido el más benigno con el derecho fundamental adecuado". ${ }^{52}$ En un sentido muy similar, Stone Sweet afirma lo siguiente: "The core of necessity analysis is the deployment of a "least restrictive means" (LRM) test: the judge ensures that the measure does not curtail the right any more than is necessary for the government to achieve its stated goals". ${ }^{53}$

Ciertamente, la Corte no está obligada de ninguna manera a usar la terminología de Alexy. En principio, el hecho de que la Corte se alejara de lo propuesto por este autor no es muy significativo. Sin embargo, en el presente caso sí es importante pues dejar ver que la Corte está más preocupada por usar el principio de proporcionalidad como una herramienta discursiva que como un método riguroso para resolver cierto tipo de problemas. En esa medida, la falta de rigor de la Corte sí es importante. Resulta sorprendente el hecho de que la Corte en ningún momento justifica el uso del PP porque es la primera vez que se usó; sin embargo, dicha novedad no mereció ningún comentario. La Corte resolvió el asunto como si el PP fuera un método

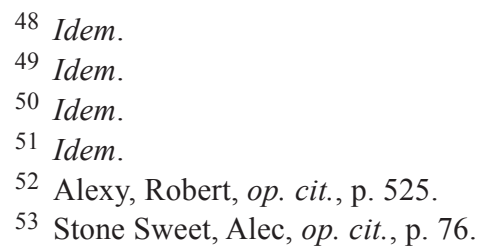


con una larga tradición en este país. ${ }^{54}$ De esta manera, la Corte genera la sensación de que el PP es un principio inherente del sistema.

Una vez que la Corte decidió aplicar un escrutinio ordinario procedió al análisis de cada uno de los pasos del PP con su correspondiente modulación. En su opinión, la finalidad (primer paso del examen) del artículo 194 es "...organizar el sistema penal de modo que esté orientado a la readaptación social del delincuente...". ${ }^{55}$ Por tratarse de un objetivo constitucionalmente admisible, la medida logró cumplir con el primer paso del examen. El segundo paso también fue superado porque "...las distinciones y requisitos introducidos por los artículos examinados están racionalmente conectados con la persecución de dicho fin...". ${ }^{56}$ Por último, sí se cumplió el tercer paso porque las distinciones y requisitos “...no incurren en desproporción alguna". ${ }^{57}$ La Corte resolvió que ninguno de los artículos violaba el derecho a la igualdad. Como el caso no involucraba la afectación de derechos fundamentales ni una clasificación sospechosa, no había necesidad de aplicar un escrutinio estricto, razón por la cual se le otorga al legislador un campo de maniobra muy amplio.

i) ¿El órgano jurisdiccional usó el PP con rigor (tomando como parámetro a los tres subprincipios mencionados por Alexy)? No. Tal como se mencionó anteriormente, la Corte no distingue claramente entre el la "necesidad" y la "proporcionalidad en sentido estricto". Además, en el análisis de la proporcionalidad no se realiza una ponderación efectiva, la Corte se limitó a mencionar que las distinciones y requisitos no eran desproporcionadas.

ii) ¿Existe una justificación para usar el PP en el presente caso? ¿Fue útil? ¿La utilización del PP aporta algo que no se hubiera podido hacer con otro método? No. De hecho, el asunto termina resolviéndose con base en el estudio de los distintos tipos de escrutinio de origen norteamericano.

54 Algo similar sucede con la doctrina en general. Resulta un ejemplo muy claro lo que hace Rubén Sánchez Gil en su libro El Principio de proporcionalidad, al dedicar todo un capítulo de su obra para proporcionar argumentos que demuestren que el PP tiene un fundamento constitucional en la Constitución Mexicana de 1917. Independientemente de lo bien documentada que está la obra, difiero completamente de esto por la sencilla razón de que el PP es una invención doctrinal y judicial que no tiene más de 60 años de existencia y, por lo tanto, no pudo haber sido previsto por el Constituyente del 17.

55 Ejecutoria de amparo en revisión 988/2004, op. cit.

56 Idem.

57 Idem. 
iii) ¿El órgano jurisdiccional acepta de manera abierta las implicaciones de usar el PP? Al contrario, la Corte insistió con fuerza en que lo hecho no puede considerarse como un juicio de oportunidad política:

Queda por supuesto excluido del ámbito de lo que esta Suprema Corte debe examinar en el ejercicio de sus funciones, la apreciación de si la distinción realizada por el legislador es la medida más óptima y oportuna para alcanzar el fin deseado; ello exigiría aplicar criterios de oportunidad política cuyo uso es totalmente ajeno a la competencia jurisdiccional de esta Corte. La misma se limita a determinar si la distinción realizada por el legislador se encuentra dentro del abanico de tratamientos que pueden considerarse proporcionales habida cuenta de la situación de hecho, la finalidad de la ley, y los bienes y derechos afectados por la misma, con independencia de que, desde ciertos puntos de vista, unos puedan considerarse preferibles a otros. ${ }^{58}$

La Corte sugiere que no hay ningún criterio de oportunidad política pues no analizó si la medida del legislador era la más óptima y oportuna para alcanzar el fin deseado. Si bien es cierto que no estudió si era la medida más óptima, sí analizó si ésta se encontraba dentro de un abanico de posibilidades, y no se ve por dónde se pueda decir que sólo lo primero implique la aplicación de criterios de oportunidad política y lo segundo no.

\section{Amparo en revisión $1629 / 2004^{59}$}

Este asunto lo resolvió la Primera Sala de la Corte el 24 de agosto de 2005. En este caso, el quejoso planteó la inconstitucionalidad de la Ley del Impuesto al Activo así como del "Decreto por el que se exime del pago de los impuestos que se mencionan y se otorgan facilidades administrativas a diversos contribuyentes" (el "Decreto"). El Decreto establecía una exención del impuesto al activo a los contribuyentes cuyos ingresos fueran menores a $\$ 14,700,000.00$ (catorce millones setecientos mil pesos $00 / 100 \mathrm{MN}$ ) anuales. Según el quejoso, esto violaba su derecho a la igualdad. Este caso es uno de los precedentes en las tesis de jurisprudencia de rubros: a) Igualdad. Criterios para determinar si el legislador respeta ese

58 Idem.

59 El ministro ponente fue José Ramón Cossío; el secretario fue Juan Carlos Roa Jacobo; el amparo se resolvió por unanimidad de cinco votos. 
principio constitucional, y b) Análisis constitucional. Su intensidad a la luz de los principios democrático y de división de poderes.

Tal como en el caso del amparo en revisión 988/2004, la Corte mezcló el examen norteamericano con el alemán. El primer paso fue determinar el tipo de escrutinio. Debido a que el asunto era de carácter fiscal y que, por lo tanto, no involucraba afectación alguna a un derecho fundamental ni se refería a alguna de las clasificaciones sospechosas, la Corte aplicó un escrutinio ordinario y, por lo tanto, suavizó todos los requisitos. A partir de eso, la Corte identificó los correspondientes subprincipios del examen alemán: a) finalidad: "determinar si la finalidad es objetiva y constitucionalmente válida. Ello, en razón de que los medios escogidos por el legislador no sólo deben guardar relación con los fines buscados por la norma, sino compartir su carácter de legitimidad"; ${ }^{60}$ b) racionalidad: "examinar la racionalidad de la medida, esto es, que exista una relación de índole instrumental entre los medios utilizados y el fin pretendido", ${ }^{61}$ y c) proporcionalidad: "valorar que se cumpla con una relación de proporcionalidad, la cual propiamente sopesa la relación de medios afines, a fin de determinar si en aras de un fin constitucionalmente válido no se afectan de manera innecesaria o excesiva otros bienes o derechos protegidos por la Constitución Federal, verificando, en su caso, si pudiera existir alguna vía menos gravosa para el derecho". ${ }^{62}$

Sobre la "finalidad" perseguida, la Corte concluyó que era "perfectamente admisible desde el punto de vista constitucional, especialmente considerando la interpretación sistemática de sus artículos 3o., 25 y 26”. Sobre el requisito de "racionalidad" (que en realidad se trata del de "idoneidad"), la Corte dijo lo siguiente:

Partiendo de la noción de que el análisis efectuado por esta Sala —no siendo estricto- no pretende encontrar una respuesta correcta única en el actuar del Poder Ejecutivo, sino que simplemente se aboca al análisis de la relación entre medios y fines -considerando que aquéllos son racionales en la medida en la que sean adecuados para alcanzar la finalidad propuesta [fomento de la pequeña y la mediana empresa]. ${ }^{63}$

60 Ejecutoria de amparo en revisión 1629/2004 (consulta 10 de febrero de 2011), disponible en http://www2.scjn.gob.mx/ius2006/UnaEj.asp?nEjecutoria $=19792 \&$ Tpo=2.

61 Idem.

62 Idem.

63 Idem. 
Según la Corte, el Decreto también cumplió con el último requisito, el de la proporcionalidad en sentido estricto, aunque en realidad nunca analizó si el Decreto cumplía o no con este requisito. De hecho, se limitó a decir que, como el asunto se refería a una regulación "económica", la decisión le correspondía por entero al Ejecutivo:

...el análisis del criterio utilizado por el Ejecutivo se efectúa bajo un parámetro débil, al tratarse de la regulación de la actividad económica — rubro éste en el que la propia Constitución establece una amplia capacidad de intervención y regulación diferenciada del Estado-, siendo legítimas las clasificaciones que, buscando la consecución de una finalidad permitida por la Constitución, sean adecuadas para tal fin. ${ }^{64}$

Por todo lo anterior, la Corte resolvió que la medida perseguía una finalidad legítima, era racional (o “idónea”) y también era proporcional.

i) ¿El órgano jurisdiccional usó el PP con rigor (tomando como parámetro a los tres subprincipios mencionados por Alexy)? No, tal como en el amparo 988/2004, la Corte no distinguió claramente entre el subprincipio de proporcionalidad y el de necesidad. Por otro lado, no se lleva a cabo una ponderación efectiva.

ii) ¿Existe una justificación para usar el PP en el presente caso? ¿Fue útil? ¿La utilización del PP aporta algo que no se hubiera podido hacer con otro método? No, y la prueba de ello es que lo determinante del resultado fue el tipo de escrutinio: el asunto terminó cuando la Corte decidió analizar el caso bajo un escrutinio ordinario.

iii) ¿El órgano jurisdiccional acepta de manera abierta las implicaciones de usar el PP? No. La Corte insiste en que no llevó a cabo una búsqueda de la única respuesta correcta en la actuación del Ejecutivo y que no sustituyó la función legislativa del Congreso o del Ejecutivo:

En efecto, en tales esferas, un control muy estricto llevaría al Juez constitucional a sustituir la función legislativa del Congreso - o la extraordinaria que puede corresponder al Ejecutivo-, pues no es función del Poder Judicial Federal, sino de los órganos políticos, entrar a analizar si esas clasificaciones económicas son las mejores o resultan necesarias. Para este Alto Tribunal es

64 Idem. 
claro que la fuerza normativa del principio democrático y del principio de separación de poderes tiene como consecuencia obvia que los otros órganos del Estado - y entre ellos, el juzgador constitucional — deben respetar la libertad de configuración con que cuentan el Congreso y el Ejecutivo, en el marco de sus atribuciones. ${ }^{65}$

Aunque es cierto que en el presente caso no se analizó si la clasificación era "la mejor", sí se analizó si era "necesaria". Difícilmente se podrá pensar en un ejemplo más paradigmático de "sustitución" de la voluntad legislativa (o de "hacer política", como se quiera) que evaluar la necesidad, idoneidad o proporcionalidad de una clasificación.

\section{Acción de inconstitucionalidad $27 / 2005^{66}$}

La Corte resolvió esta acción de inconstitucionalidad el 9 de julio de 2007. En este caso, el procurador General de la República (el "procurador") alegó la inconstitucionalidad de la Ley de Desarrollo Sustentable de la Caña de Azúcar (la "Ley de Azúcar") por considerar que violaba ciertos derechos fundamentales. En 2005 el Congreso expidió la Ley de Azúcar en un intento por remediar los problemas que afectaron a la industria azucarera mexicana. Entre otras cosas, esta ley estableció el Centro de Investigación Científica y Tecnológica de la Caña de Azúcar (Citcaña) así como un mecanismo obligatorio mediante el cual los Industriales y las Organizaciones Nacional de Abastecedores de Caña de Azúcar tenían que hacer contribuciones obligatorias. El procurador argumentó que el mecanismo resultaba inconstitucional por no existir un fundamento para exigir dichas contribuciones. En lugar de declarar el mecanismo como inconstitucional, la Corte recurrió a una "interpretación conforme" ${ }^{67}$ En pocas palabras, la Corte dijo que dado que el Citcaña no podía funcionar sin recursos, no declararía la

65 Idem.

66 El ministro ponente fue Juan N. Silva Meza; estuvieron ausentes los ministros Luna Ramos, Cossío, Góngora y Gudiño; la secretaria fue Guillermina Coutiño; la acción se resolvió por mayoría de seis votos, razón por la cual no tuvo efectos generales.

67 La "interpretación conforme" es una herramienta que permite interpretar una disposición que tiene dos o más posibles sentidos, en el sentido que vaya de acuerdo con la Constitución. Actualmente ya hay jurisprudencia sobre este principio: Principio de interpretación de la ley conforme a la Constitución (consulta 10 de febrero de 2011), formato html, disponible en http://www2.scjn.gob.mx/ius2006/UnaTesislnkTmp.asp? nIus $=16330$ $0 \& c$ PalPrm $=$ INTERPRETACION,CONFORME, \& $c$ FrPrm $=$. 
inconstitucionalidad del mecanismo de contribuciones con la condición de que dichas contribuciones fueran voluntarias. De esta acción de inconstitucionalidad se deriva la siguiente tesis aislada de rubro: Interpretación conforme en acciones de inconstitucionalidad, cuando una norma admita varias interpretaciones debe preferirse la compatible con la Constitución.

Al contrario de lo que ocurrió en los casos estudiados anteriormente, la Corte no analiza paso a paso los tres requisitos del PP; sin embargo, sí recurre a una ponderación (aunque no de "principios") en un sentido muy similar a la ley de la ponderación y, en esa medida, es posible hablar del uso del PP.

Este Tribunal Constitucional en todos los casos en que se cuestiona la constitucionalidad de una disposición legal, debe hacer un juicio de razonabilidad a partir de un ejercicio de ponderación para verificar el peso de las razones que pudieran motivar la declaración de invalidez de una norma, por ser contraria u opuesta a un postulado constitucional, frente al peso derivado de que la disposición cuestionada es producto del ejercicio de las atribuciones del legislador y que puede ser objeto de una interpretación que la haga acorde con los contenidos de la Ley Suprema, debiendo prevalecer el que otorgue un mejor resultado para lograr la observancia del orden dispuesto por el Constituyente y el Órgano Reformador de nuestra Norma Suprema. ${ }^{68}$

Como se puede ver, el discurso de la Corte es propio del PP: razonabilidad, ponderación, pesos, etc. Sin embargo, es sorprendente que a pesar de esto, en el caso concreto no es posible distinguir una colisión de derechos fundamentales o una ponderación de un derecho fundamental frente a un interés legítimo del gobierno. La ponderación no ocurrió entre principios sino entre las "razones para usar la interpretación conforme" y las "razones para declarar la inconstitucionalidad de una ley". Al final, la Corte concluyó que las razones para efectuar una interpretación conforme pesaban más que las razones para declarar la inconstitucionalidad de la ley.

i) ¿El órgano jurisdiccional usó el PP con rigor (tomando como parámetro a los tres subprincipios mencionados por Alexy)? No, la Corte se limitó a usar la terminología propia del PP de manera desordenada, como si para ponderar principios o derechos bastara con lanzar al aire

68 Ejecutoria de acción de inconstitucionalidad 27/2005 (consulta 10 de febrero de 2011), disponible en http://www2.scjn.gob.mx/ius2006/UnaEj.asp? nEjecutoria $=20569 \&$ Tpo=2. 
términos como "ponderación”, "peso", "principios”, "proporcionalidad" o "razonabilidad".

ii) ¿Existe una justificación para usar el PP en el presente caso? ¿Fue útil? ¿La utilización del PP aporta algo que no se hubiera podido hacer con otro método? De ninguna manera. Este asunto se resolvió con base en el método de la interpretación conforme y en realidad el PP y la ponderación no jugaron ningún papel.

iii) ¿El órgano jurisdiccional acepta de manera abierta las implicaciones de usar el PP? No, aunque en realidad ni siquiera existía dicha posibilidad pues el caso no involucraba derechos fundamentales o principios. El caso es relevante porque demuestra, creo, la disposición de la Corte para valerse de la ponderación y del PP para resolver cualquier tipo de asunto. ${ }^{69} \mathrm{Al}$ actuar de este modo, la Corte genera la sensación de que el PP es, como dice Alec Stone Sweet, un principio inherente del sistema que puede ser usado para todo tipo de casos.

\section{Amparo en revisión 307/2007 70}

Este amparo en revisión, resuelto por el Pleno de la Corte el 24 de septiembre de 2007, es uno de los casos que más atención ha recibido en los últimos años. El problema surgió debido a que varios miembros de las fuerzas armadas mexicanas fueron retirados del servicio en razón de que el artículo 226, segunda categoría, fracción 45, de la Ley de Instituto de Seguridad Social para las Fuerzas Armadas Mexicanas (la "Ley de Fuerzas Armadas") los consideraba como "inútiles" por estar infectados con VIH.

69 El PP ha cobrado tal fuerza que incluso se puede encontrar en asuntos no jurisdiccionales, tales como la resolución de la Corte en el caso Atenco, en el que para evaluar el uso de la fuerza utilizó un "test de razonabilidad" tributario del PP. Por si esto fuera poco, ya se empieza a notar un fenómeno que Alec Stone Sweet ubicó en Europa (op. cit.), especialmente el capítulo 3, (Legislating): el uso creciente por parte de los Poderes Legislativos de un discurso propio de los tribunales constitucionales. Como ejemplos de esto se pueden señalar la Minuta con Proyecto de Decreto por el que se expide la Ley que Regula el uso de la Fuerza por los Integrantes de las Instituciones de Seguridad Pública, aprobada por la Cámara de Diputados el 28 de abril de 2009, que actualmente se encuentra en la Cámara de Senadores. En dicho documento, por ejemplo, se establece que el uso de la fuerza debe ser: idóneo, necesario y proporcional.

70 El ministro ponente fue Juan N. Silva Meza; se manifestaron en contra los ministros Góngora, Azuela y Aguirre, y el secretario fue Manuel González Díaz; el amparo se resolvió por mayoría de 8 votos. 
Este asunto participó como precedente de las tesis de jurisprudencia de rubros: a) Garantías individuales. el desarrollo de sus límites y la regulación de sus posibles conflictos por parte del legislador debe respetar los principios de razonabilidad y proporcionalidad jurídica, y b) Seguridad social para las Fuerzas Armadas Mexicanas. El artículo 226, segunda categoría, fracción 45, de la Ley del Instituto Relativo, que prevé la causa legal de retiro por inutilidad basada en la seropositividad a los anticuerpos contra el Virus de la Inmunodeficiencia Humana (VIH), viola el artículo 1o. de la Constitución federal.

La Corte decidió emprender el análisis del caso a partir de la colisión del derecho a la igualdad con el principio de la eficacia de las fuerzas armadas mexicana. ${ }^{71}$ A pesar de que el caso involucraba una discriminación por razón de salud (y encuadrable, por lo tanto, bajo la categoría de "clasificación sospechosa" mencionada en el amparo en revisión 988/2004), en lugar de utilizar un "escrutinio estricto", la Corte se limitó a usar un "escrutinio ordinario”. ¿Por qué? Según la Corte, porque las fuerzas armadas están sujetas a un régimen de excepción: “....este tribunal determina que el caso merece un tratamiento particular, por estar comprendido dentro de lo que la doctrina denomina relación de sujeción especial, derivada del señalado régimen de excepción que el Texto Constitucional prevé para los militares". ${ }^{72}$

Para resolver el caso, la Corte utilizó un examen similar al usado en casos anteriores salvo que, en el presente caso, se incorporó el requisito de "razonabilidad" (en realidad se trata del de "proporcionalidad") y que ya se menciona expresamente el subprincipio de "necesidad": a) finalidad constitucionalmente legítima; b) adecuación o idoneidad, esto es, “....susceptible de alcanzar la finalidad constitucional perseguida...", ${ }^{73} c$ ) necesidad, “... suficiente para alcanzar la finalidad constitucionalmente legítima, de tal forma que no implique una carga desmedida e injustificada para el gobernado respectivo", ${ }^{74} \mathrm{y} d$ ) razonabilidad, esto es, que “...cuanto más intenso sea el

71 Es pertinente mencionar (aunque esto se detallará más adelante) que en su voto concurrente, el ministro Cossío manifestó su inconformidad respecto de la identificación de la eficacia de las fuerzas armadas como principio.

72 La Corte no se tomó la molestia de aclarar cuál es la doctrina que desarrolla este tema.

73 Ejecutoria de amparo en revisión 307/2007 (consulta 10 de febrero de 2011), disponible en http://www2.scjn.gob.mx/ius2006/UnaEj.asp? nEjecutoria $=20915 \&$ Tpo $=2$.

74 Idem. 
límite de la garantía individual, mayor debe ser el peso o jerarquía de las razones constitucionales que justifiquen su intervención...". ${ }^{75}$

$\mathrm{Al}$ analizar la medida legislativa bajo el examen mencionado, la Corte resolvió que la norma en cuestión violaba el derecho a la igualdad. En opinión de los ministros, si bien dicho artículo perseguía un objetivo legítimo (la eficacia de las fuerzas armadas), también lo es que no cumplía con los otros tres requisitos. La Corte consideró lo siguiente:

...la diferenciación legal es inadecuada para alcanzar dicha finalidad constitucional legítima, porque la ciencia médica ...han demostrado la inexactitud de la decisión... de que los militares son inútiles y están incapacitados per se para formar parte del Ejército, por el simple hecho de tener seropositividad a los anticuerpos contra el virus de la inmunodeficiencia humana... ${ }^{76}$

Además, consideró que la medida no era necesaria y, por lo tanto, desproporcionado, porque: "el traslado a un área distinta, y no el retiro complementado con la sustracción de los derechos prestacionales de salud que corresponden en activo, sería una alternativa menos gravosa para el individuo en relación con el goce y ejercicio de sus garantías individuales...". ${ }^{77}$ Por último, consideró que no era razonable porque:

la diferenciación legislativa reclamada carece de razonabilidad jurídica, en virtud de que no existen bases para justificar la equiparación que ha hecho el legislador del concepto de inutilidad con el de enfermedad o, en este caso, con la seropositividad a los anticuerpos contra el virus de la inmunodeficiencia humana... ${ }^{78}$

Esto puede decirse en otras palabras: el artículo no es razonable, pues, precisamente, porque no es razonable, o sea, porque no. Dado que la disposición también resultaba inadecuada e innecesaria, la Corte decidió declarar inconstitucional el artículo en cuestión. No es que esté en desacuerdo con la conclusión pero la argumentación es muy deficiente.

$\begin{array}{ll}{ }^{75} & \text { Idem. } \\ 76 & \text { Idem. } \\ { }^{7} & \text { Idem. } \\ { }^{77} & \text { Idem } \\ 78 & \text { Idem. }\end{array}$ 
i) ¿El órgano jurisdiccional usó el PP con rigor (tomando como parámetro a los tres subprincipios mencionados por Alexy)? No. En primer lugar, la Corte nunca menciona al subprincipio de proporcionalidad en sentido estricto porque lo confunde con la "razonabilidad". ${ }^{79}$ Por otro lado, nunca da un solo argumento para justificar la decisión de que las fuerzas armadas están sujetas a un régimen especial: una simple referencia a la "doctrina" no es un argumento convincente. Además, su caracterización como principio de la "eficacia de las fuerzas armadas" es más que dudosa. De hecho, el ministro Cossío emitió un voto concurrente en el que señala la imposibilidad de agrupar las disposiciones sobre las fuerzas armadas impedían agruparlas bajo la categoría de "principio" debido a su heterogeneidad. Para él, el choque no se dio entre principios sino entre un principio (igualdad y no discriminación) y una medida legislativa no idónea. ${ }^{80}$

ii) ¿Existe una justificación para usar el PP en el presente caso? ¿Fue útil? ¿La utilización del PP aporta algo que no se hubiera podido hacer con otro método? Si bien creo que en este caso el PP sí fue útil, el problema no es con el uso del PP sino con la deficiente argumentación y con la falta de transparencia en los argumentos de la Corte.

iii) ¿El órgano jurisdiccional acepta de manera abierta las implicaciones de usar el PP? No. De hecho, la Corte no sólo no reconoce esto sino que se esfuerza por encontrar un fundamento constitucional al PP: "En el sistema jurídico mexicano, el PP puede deducirse del Texto Supremo, básicamente como exigencia del principio de legalidad; de la prohibición constitucional que exige al legislador no actuar en exceso de poder o de manera arbitraria". ${ }^{81}$ La Corte llega a poner como ejemplo del reconocimiento del PP por ciertos órganos jurisdiccionales algunas tesis de la Quinta Época, es decir, tesis emitidas entre el 1o. de junio

79 De conformidad con lo que menciona el ministro Cossío en su voto particular, en derecho constitucional comparado se consideran como sinónimos el juicio de razonabilidad y el juicio de proporcionalidad. Sin embargo, también existen autores que no están de acuerdo con esta identificación. Sobre este tema vale la pena consultar a Bernal Pulido, Carlos, "El juicio de la igualdad en la jurisprudencia de la Corte Constitucional Colombiana" (consulta 10 de febrero de 2011), formato html, disponible en http://190.41.250.173/ rij/bases/nodiscriminacion/BERNAL.PDF.

80 Voto concurrente del ministro José Ramón Cossío en el amparo en revisión 307/2007 (consulta 10 de febrero de 2011), disponible en http://www2.scjn.gob.mx/ius2006/UnaEj. asp? $n$ Ejecutoria $=20953 \&$ Tpo $=3$.

81 Ejecutoria del amparo en revisión 307/2007, op. cit. 
de 1917 y el 30 de junio de 1957. Como se mencionó anteriormente, esto es sencillamente imposible porque el PP (como herramienta para resolver casos de colisión de principios entre sí o de principios frente a algún interés estatal legítimo) se empezó a usar por tribunales constitucionales a mediados del siglo XX.

\section{Acción de inconstitucionalidad 11/2005 82}

En esta acción de inconstitucionalidad, resuelta por la Corte el 8 de noviembre de 2008, el procurador argumentó la inconstitucionalidad de una ley estatal del estado de Colima que prohibía a los menores de dieciocho años trabajar en establecimientos en los que se vendiera alcohol o participar en campañas publicitarias relacionadas con campañas alcohólicas. El Procurador consideró que la ley era inconstitucional porque la facultad para legislar en materia laboral es exclusiva de la Federación. La Ley Federal del Trabajo (la "Ley del Trabajo"), por cierto, establece la misma prohibición pero para los menores de dieciséis. El estado de Colima expidió la ley en cuestión en uso de las facultades concurrentes de combate al alcoholismo. De esta acción se derivó la siguiente tesis aislada de rubro: MENORES DE DIECIOCHO AÑOS. EL ANÁLISIS DE UNA REGULACIÓN RESPECTO DE ELLOS DEBE HACERSE ATENDIENDO AL INTERÉS SUPERIOR Y A LA PRIORIDAD DE LA INFANCIA.

Al igual que en la acción de inconstitucionalidad 27/2005, la ponderación no se da entre derechos o principios sino entre algo más. En esta acción el choque ocurrió entre las atribuciones del gobierno federal y las del gobierno estatal. "En el caso, no existe una colisión de valores entre libertad de trabajo y combate al alcoholismo. Más bien, lo que existe es una colisión de atribuciones entre potestades exclusivas de la Federación para emitir leyes sobre el trabajo, y potestades de los estados para emitir leyes que tiendan a combatir el alcoholismo" ${ }^{83}$ En sentido estricto, la facultad de la Federación para legislar en materia de trabajo chocó con la facultad concurrente de los Estados y de la Federación para legislar con el propósito de combatir el

82 El ministro ponente fue Sergio Valls; estuvieron ausentes los ministros Góngora y Cossío; la secretaria fue Laura García Velasco; la acción se resolvió por mayoría de seis votos, razón por la cual no tuvo efectos generales y por la cual no formó jurisprudencia.

83 Ejecutoria de acción de inconstitucionalidad 11/2005 (consulta 10 de febrero de 2011), disponible en http://www2.scjn.gob.mx/ius2006/UnaEj.asp? nEjecutoria $=20776 \&$ Tpo $=2$. 
alcoholismo. ${ }^{84}$ Lo anterior es una muestra más de que la Corte usa el PP más como una herramienta discursiva para consolidar su papel de tribunal constitucional que como un método para solucionar casos concretos.

Como muestra basta un botón. Justo después de mencionar que no existe colisión entre "valores" sino entre poderes o atribuciones la Corte dice: "de esta forma, debe tenerse en cuenta la preponderancia de valores: por un lado, la libertad de trabajo que, como se ha reconocido, no es absoluta, y, por otro lado, el combate al alcoholismo, la protección a menores de edad y el derecho a la salud que, se considera, tienen un peso específico de mayor relevancia". ${ }^{85}$ La Corte en ningún momento da razones para apoyar que en el caso concreto la protección de los menores tiene un mayor peso específico La fórmula de Alexy, con todo y las fallas metodológicas mencionadas, al menos parte de la base de que hay que asignar ciertos valores para hacer el cálculo del peso específico. En el presente caso, sin embargo, el peso específico parece ser más bien el producto de una corazonada o una intuición que de un cálculo como el que sugiere Alexy.

Justo después de analizar la colisión entre atribuciones, la Corte analiza la racionalidad de la disposición:

Es claro que el artículo 117 constitucional al establecer una facultad concurrente entre el Congreso de la Unión y las Legislaturas Estatales, con la finalidad de combatir el alcoholismo y el enjuiciamiento de la constitucionalidad de leyes que combaten el alcoholismo, debe juzgarse solamente en función de la racionalidad de sus disposiciones. ${ }^{86}$

Sólo como apunte, me cuesta trabajo imaginar un acto más "político" (en el sentido detallado al principio de este trabajo) que analizar la racionalidad de una disposición legislativa. Ya para terminar, la Corte concluye de la siguiente manera:

En este sentido, tanto de lo dispuesto en el artículo 4o. de la Norma Fundamental, como de la exposición de motivos de la Ley para la Protección de los Derechos de Niñas, Niños y Adolescentes, reglamentaria de aquél, se desprende

84 Sobre el tema de facultades concurrentes hay una amplia bibliografía; sin embargo, resultan especialmente recomendables; Arteaga, Elisur, Derecho constitucional, México, Oxford, 1999; Carpizo, Jorge, Estudios constitucionales, México, Porrúa, 1999, y Tena Ramírez, Felipe, Derecho constitucional mexicano, México, Porrúa, 2000.

85 Ejecutoria de acción de inconstitucionalidad 11/2005, op. cit.

86 Idem. 
la intención de establecer una jerarquía en las garantías constitucionales de los niños y adolescentes, estableciendo como prioritario - en un ejercicio de ponderación - el reconocimiento del derecho a la protección para que los menores crezcan en un ambiente que no interfiera en su desarrollo físico y mental, sobre cualquier otra garantía ${ }^{87}$, en este particular caso, las de tipo económico, como es la libertad de trabajo, la cual, como ha sustentado este Alto Tribunal, es limitada. ${ }^{88}$

Lo hecho por la Corte se puede resumir de la siguiente manera: primero, reconoce que el gobierno federal tiene la facultad para legislar en materia laboral; segundo, admite que tanto la Federación como los estados pueden legislar para combatir el alcoholismo, cada uno dentro de su competencia. Sin embargo, como el caso involucraba los derechos de los niños, la Corte decidió que la legislación estatal debería de prevalecer sobre la facultad de la Federación. A pesar de que la Corte no analizó los tres subprincipios del PP, sí menciona a la ponderación. Al final de cuentas, la Corte optó por la constitucionalidad de la ley estatal porque los derechos de los niños gozan de un mayor peso específico.

i) ¿El órgano jurisdiccional usó el PP con rigor (tomando como parámetro a los tres subprincipios mencionados por Alexy)? No, la Corte se limitó a comparar las atribuciones de la Federación con las de los Estados y al debate le agregó una pizca de derechos de los niños. En ningún momento se preocupó por analizar si se cumplían o no los subprincipios del PP.

ii) ¿Existe una justificación para usar el PP en el presente caso? ¿Fue útil? ¿La utilización del PP aporta algo que no se hubiera podido hacer con otro método? No. Si bien el PP puede ser un método útil para resolver cierto tipo de casos (colisión entre principios o entre un principio y una medida estatal), se antoja difícil o forzado, o ambas cosas, usarlo para resolver un conflicto de atribuciones entre distintos órdenes jurídicos.

iii) ¿El órgano jurisdiccional acepta de manera abierta las implicaciones de usar el PP? No. Éste es uno de los casos más representativos de lo

87 Se supone que la ponderación sirve para resolver problemas en los que no es posible establecer una solución de todo o nada; sin embargo, esto parece no ser lo que dice la Corte, pues reconoce que el derecho "a la protección para que los menores crezcan en un ambiente que no interfiera en su desarrollo físico y mental" debe prevalecer sobre cualquier otro. ¿Entonces para qué ponderar?

88 Ejecutoria de acción de inconstitucionalidad 11/2005, op. cit. 
que hace la Corte (o de lo que deja de hacer) cuando usa el PP. La Corte parece sugerir que llegó a la conclusión (que la legislación estatal debía prevalecer sobre la federal por el interés superior de los niños) casi de manera mecánica; sin embargo, es claro que para arribar a dicha conclusión es necesario llevar a cabo una decisión política. Con todo y las complicaciones de un caso como éste (conflicto de atribuciones de distintos órdenes normativos), el método para resolverlo es más o menos sencillo: bastaba con determinar qué orden jurídico tiene la atribución para legislar en esta materia. En realidad, la Corte claramente tomó una decisión política y quiso maquillarla de racionalidad y neutralidad mediante el uso del PP.

\section{Amparo en revisión 2044/200889}

Este amparo en revisión surgió a partir de un caso muy publicitado. El editor de un periódico local del municipio de Acámbaro, Guanajuato, publicó una entrevista al ex chofer del presidente municipal. El entrevistado dijo que el presidente municipal no sólo usaba dinero del erario público para su propio beneficio sino que incluso llegó a cuestionar la sexualidad de su antiguo patrón al contar que un día éste le pidió que le sobara la espalda mientras se encontraba desnudo. El asunto lo resolvió la Primera Sala de la Corte el 18 de noviembre de 2008.

El presidente municipal denunció al editor del periódico. Eventualmente fue condenado a una pena de tres años, un mes y quince días, que luego se sustituyó por trabajo a favor de la comunidad. Como consecuencia, el editor promovió un amparo que llegó a la Corte. En dicho amparo, combatía tanto la sentencia como la ley con base en la cual se dictó la resolución, la Ley de Imprenta del Estado de Guanajuato (la "Ley de Imprenta"). Este caso es precedente de diversas tesis aisladas; sin embargo, por la relación con el presente trabajo, sólo se mencionará la tesis de rubro: Derecho a la vida privada. Su contenido es variable tanto en su dimensión interna como externa.

En este amparo se dio una colisión entre el derecho a la libertad de expresión y el derecho al honor. ${ }^{90}$ La Corte llevó a cabo un análisis tanto de la

89 El ministro ponente fue José Ramón Cossío; los secretarios fueron Roberto Lara Chagoyán y Francisca María Pou Giménez; el amparo en revisión se resolvió por unanimidad de cinco votos.

90 La Corte caracteriza al derecho al honor como el derecho "... a no ser objeto de ataques desproporcionados que destruyan su reputación y buen nombre ante los demás”. En 
resolución del Tribunal Colegiado en la que se negó el amparo como de la propia Ley de Imprenta. Por un lado, concluyó que la Ley de Imprenta era inconstitucional por no hacer una correcta "ponderación legislativa". Por el otro, sostuvo que la decisión del Colegiado reflejaba un entendimiento erróneo del papel de una ley en el desarrollo y concreción de los derechos fundamentales, así como sobre la manera de resolver un conflicto entre derechos.

\section{A. Ponderación en la Ley de Imprenta}

Se sabe que todos los derechos fundamentales son relativos. En el caso del derecho a la libertad de expresión, se prevén ciertas restricciones (que pueden desarrollarse por el legislador) en los artículos 6o. y 7o. constitucionales. Sin embargo, de la posibilidad de establecer restricciones no es posible admitir cómo válida cualquier tipo de restricción. Según la Corte, la Ley de Imprenta no llevó a cabo una correcta ponderación debido a que en ningún momento tomó en cuenta para suavizar las restricciones a la libertad de expresión las características particulares del presidente municipal. En su opinión cualquier restricción al derecho a la libertad de expresión se debe aplicar de manera menos estricta que en un caso ordinario. ${ }^{91}$ La justificación: la importancia del derecho a la información de la población para estar al tanto del comportamiento de los servidores públicos:

...para que la exigencia de responsabilidades ulteriores por emisión de discurso (especialmente protegido) alegadamente invasor del honor de funcionarios públicos u otras personas relacionadas con el ejercicio de funciones públicas constituya una reacción jurídica necesaria, idónea y proporcional, deben satisfacerse al menos las siguientes condiciones. ${ }^{92}$

contraste, el derecho a la privacidad o intimidad en sentido estricto se refiere al "...ámbito de lo que legítimamente se desea mantener fuera del conocimiento de los demás". Véase Ejecutoria de amparo en revisión 2044/2008 (consulta 10 de febrero de 2011), formato html, disponible en http://www2.scjn.gob.mx/expedientes/.

91 Las restricciones a las que se refieren son las previstas en la propia Constitución: vida privada, orden público, derechos de tercero, moral y paz pública (artículos 6o. y 7o. constitucionales).

92 Ejecutoria de amparo en revisión 2044/2008, op. cit. 
Dichas condiciones son las siguientes:

Cobertura legal y redacción clara: las causas por las que pueda entrar en juego la exigencia de responsabilidad deben constar en una ley, tanto en sentido formal como en sentido material...;93

Intención específica o negligencia patente: las expresiones e informaciones deben analizarse bajo el estándar de la "malicia", esto es, bajo un estándar que exige que la expresión que alegadamente causa un daño a la reputación de un funcionario público haya sido emitida con la intención de causar ese daño, con conocimiento de que se estaban difundiendo hechos falsos, o con clara negligencia respecto de la revisión de la aparente veracidad o falta de veracidad de los mismos (recordemos la diferencia entre veracidad y verdad anteriormente apuntada)...;94

Materialidad y acreditación del daño.... ${ }^{95}$

Doble juego de la exceptio veritatis: la persona que se expresa debe siempre poder bloquear una imputación de responsabilidad ulterior probando que los hechos a los que se refiere son ciertos y, complementariamente, no puede ser obligada a probar, como condición sine qua non para evitar esa responsabilidad, que los hechos sobre los cuales se expresó son ciertos...,96

Gradación de medios de exigencia de responsabilidad..., ${ }^{97} \mathrm{y}$

Minimización de las restricciones indirectas... ${ }^{98}$

Como la Ley de Imprenta no tomó en cuenta estas consideraciones, la Corte consideró que no existía una correcta "ponderación legislativa". Estamos de acuerdo en las críticas a la Ley de Imprenta. Ciertamente, se puede decir que su redacción ensancha de modo inaceptable las restricciones a la libertad de expresión previstas en la Constitución. Basta ver cómo caracteriza esta ley a la "vida privada" para entender las objeciones de la Corte:

Artículo 1. Toda manifestación o expresión maliciosa hecha verbalmente o por señales en presencia de una o más personas, o por medio de manuscrito, o de la imprenta, del dibujo, litografía, fotografía o de cualquier otra manera que expuesta o circulando en público, o transmitida por correo, telégrafo,
93 Idem.
${ }^{94}$ Idem.
95 Idem.
${ }^{96}$ Idem.
97 Idem.
98 Idem. 
teléfono, radiotelegrafía o por mensaje, o de cualquier otro medio, exponga a una persona al odio, desprecio o ridículo, o pueda causarle demérito en su reputación o en sus intereses. ${ }^{99}$

La redacción es tan vaga que no se necesita hacer un esfuerzo interpretativo mayor para encuadrar en dicho supuesto casi a cualquier comentario, lo cual se traduce en un una restricción de la libertad de expresión. Así, estamos en que el legislador no puede (a riesgo de violar un derecho fundamental) usar este tipo de redacciones porque se presta para incluir dentro de la categoría de "vida privada" conductas que no necesariamente lo son.

Como se puede ver, la Corte no analizó si la Ley de Imprenta cumplía o no con cada uno de los subprincipios del PP y se limitó a establecer ciertas condiciones indispensables para que una ley del tipo que se analiza sea necesaria, idónea y proporcional. La ausencia de estas condiciones impedía un análisis integral de las particularidades que se deben tomar en cuenta: "en conclusión: los artículos de la Ley de Imprenta del Estado de Guanajuato sobre cuya base fue condenado el quejoso no permiten al juzgador penal hacer el tipo de análisis global de los hechos exigible en esos casos". ${ }^{100}$

\section{B. Ponderación del Tribunal Colegiado}

La Corte manifestó su desacuerdo con la resolución del Tribunal Colegiado debido a que no ponderó adecuadamente el derecho al honor y a la vida privada de los funcionarios públicos con la libertad de informar de los periodistas. La Corte criticó con dureza la equiparación que hizo el Colegiado entre "vida sexual" y "vida privada". Además, consideró que el tribunal cometió un error pues las reglas de ponderación lo obligaban a tomar en cuenta el carácter de servidor público del involucrado. Si el Colegiado — según la Corte- hubiera tomado en cuenta lo anterior, le habría reconocido mayor peso al derecho a la libertad de informar:

Las reglas de ponderación, tanto abstracta como concreta, entre los derechos enfrentados, debían tener en cuenta estas circunstancias porque el peso que en el caso debía serles reconocido se anuda en parte a este factor, que obviamente no se asienta en la calidad o las características intrínsecas de los citados sujetos, sino en el tipo de interés público asociado a las actividades que realizan.

${ }^{99}$ Idem.

$100 \mathrm{Idem}$. 
Comparto plenamente el criterio de que las restricciones a la libertad de expresión deben suavizarse si en el caso concreto están involucrados servidores públicos. En opinión de la Corte, ahí es donde justamente se equivoca el Colegiado, pues su interpretación

es incorrecta, en tanto traza una equivalencia auténtica entre "vida sexual" y "vida privada" y en tanto soslaya o mezcla los diversos significados de esta expresión, y es incompleta porque olvida la relevancia de analizar el tipo de sujetos que ejercen en el caso concreto los derechos constitucionales en conflicto: el hecho, en el caso de autos, de que el titular del derecho a la vida privada cuyos derechos se afirma se quieren preservar mediante la aplicación de la ley penal sea o haya sido un funcionario público, y el hecho de que el quejoso no sea un ciudadano cualquiera, sino alguien que se dedica profesionalmente al mundo de la comunicación en medios impresos, profesionalmente vinculado al mundo del periodismo. ${ }^{101}$

Entiendo y comparto la consideración de que las restricciones a la libertad de expresión deben suavizarse cuando están involucrados servidores públicos (u otro tipo de figuras públicas); sin embargo, no veo cómo esto deba alcanzar la conducta sexual. Ciertamente existe un interés de los ciudadanos en enterarse si un presidente municipal utiliza recursos públicos para uso propio, pero a menos que se trate de una estrella de la industria pornográfica, se antoja difícil encontrar un comportamiento más "privado" que el sexual. En lugar de hacer una ponderación de derechos fundamentales en el caso concreto, la Corte estableció una especie de "regla general" que resulta un tanto incompatible con el análisis casuístico con el PP?

i) ¿El órgano jurisdiccional usó el PP con rigor (tomando como parámetro a los tres subprincipios mencionados por Alexy)? Si bien la Corte no hace un paso a paso de cada uno de los subprincipios en relación con la Ley de Imprenta, sí señala cuáles son las condiciones para que la medida legislativa sí sea necesaria, idónea y proporcional. En medida en que se omite el análisis de los subprincipios, es posible hablar de una cierta falta de rigor; sin embargo, la omisión no parece tan grave en vista de lo dicho anteriormente. 
Por otro lado, en el análisis de la resolución del Tribunal Colegiado y en la solución al choque de principios, sí se aprecia una falta de rigor. Esto es así por dos razones. Primero, porque el único subprincipio que se usa es el del mandato de la ponderación. Segundo, porque no se dan argumentos para justificar la razón por la cual en el caso concreto el derecho de informar de los periodistas tenía más peso que el derecho al honor del presidente municipal.

ii) ¿Existe una justificación para usar el PP en el presente caso? ¿Fue útil? ¿La utilización del PP aporta algo que no se hubiera podido hacer con otro método? Como ya se ha dicho, el PP puede ser especialmente útil para resolver colisiones de derechos fundamentales. Sin embargo, en el caso concreto no se utilizó con todo rigor pues no se levó a cabo una ponderación concreta de los dos derechos en conflicto sino que se estableció una especie de "regla general": la decisión ya estaba tomada de antemano desde el momento en que la Corte decidió analizar todo a partir de la relajación de las restricciones a la libertad de expresión por estar involucrado un servidor público. ${ }^{102}$

iii) ¿El órgano jurisdiccional acepta de manera abierta las implicaciones de usar el PP? No. Resulta especialmente representativa la conclusión de la Corte: "finalmente, tampoco permite [la Ley de Imprenta] dar un tratamiento justo a conductas cuyo adecuado y proporcional tratamiento jurídico, a la vista de las previsiones de nuestras Carta Magna, exigiría el uso de alternativas menos gravosas para los derechos fundamentales, lejanas al derecho penal". ${ }^{103}$

Podemos estar de acuerdo con que la sanción prevista en la Ley de Imprenta es desproporcionada; sin embargo, para desprender esa conclusión de "las previsiones de nuestra carta magna" se necesita una labor interpretativa considerable y tomar una postura de carácter política al momento de elegir a las "alternativas menos gravosas". La Corte, en cambio, plantea esto como si su conclusión estuviera ya contenida en el texto constitucional.

102 De hecho, si la Corte estaba dispuesta a ser tan rigurosa en el análisis de las particularidades del caso, debió haber tomado en cuenta que no es lo mismo acusar de una conducta homosexual en la Ciudad de México que en Acámbaro, Guanajuato.

103 Ejecutoria de amparo en revisión 2044/2008, op. cit. 


\section{CONCLUSIONES}

Durante los últimos años, la Corte ha logrado ocupar una posición protagónica en la arena pública. En la consolidación de este nuevo rol como un actor político capaz de interactuar con cualquier otro, el PP ha demostrado ser una herramienta sumamente útil. Mediante el uso de esta herramienta, la Corte ha logrado presentar una imagen de tribunal constitucional moderno a la par de los tiempos que corren. Atrás ha quedado la imagen de una Corte pasiva y un tanto ajena a la teoría constitucional contemporánea. Pero además, y acaso esto sea lo más importante, el PP ha servido para otra cosa: gracias a esta herramienta analítica e interpretativa, la Corte se ha podido involucrar de lleno en decisiones netamente políticas sin necesidad de sufrir el desgaste normal y cotidiano (wear and tear, dirían los norteamericanos) propios de involucrarse en la actividad política.

Así, por un lado, la corte es crecientemente un actor político con capacidad para entrar en pie de igualdad con los demás poderes en el sistema, y por el otro, pretende crearse la imagen de que está por encima de las disputas políticas y de que sus decisiones son independientes de las consecuencias que puedan tener. Esta paradoja entraña un gran riesgo, justo en la medida en que la corte enmascara su renovado activismo con el velo del lenguaje jurídico y pretende en ocasiones ponerse por encima de los otros poderes. ${ }^{104}$

Esto se dijo en 2002, antes de que la Corte empezara a usar el PP. Actualmente suena incluso más certero. Aclaremos que no hay nada negativo per se en el uso del PP. Tan sólo afirmo que cuando se usa de cierta manera, no es posible obtener sus beneficios: transparentar las decisiones de los jueces. Si lo usamos incorrectamente, imposibilitamos la discusión pública de las resoluciones judiciales. La razón por la cual es importante discutir las resoluciones de la Corte es que encima de ésta no hay nadie salvo nosotros: los ciudadanos, los abogados, los politólogos, los intelectuales, los no especialistas, etcétera. La importancia de esta discusión ya la destacaba desde hace algún tiempo el ahora ministro Zaldívar:

No basta con enterarnos del sentido de los fallos de la Corte, ni siquiera cuando éstos coinciden con lo políticamente correcto. Es indispensable el

104 González Compeán, Miguel y Bauer, Peter, Jurisdicción y democracia. Los nuevos rumbos del Poder Judicial, México, Cal y Arena, 2002, p. 364. 
estudio de los argumentos esgrimidos en las resoluciones y de las razones que, en su caso, aportaron quienes integraron la minoría. La Suprema Corte es el órgano límite del orden jurídico mexicano. Sus resoluciones no están sujetas a revisión alguna de derecho interno, sus fallos son definitivos e inatacables. El único control social sobre el trabajo de la Corte es el que realizan la academia, el foro y los medios de comunicación al analizar las sentencias de la Corte y destacar suS aciertos y sus errores. ${ }^{105}$

Hemos dicho que, a pesar de sus deficiencias metodológicas, el PP puede resultar muy útil para resolver cierto tipo de asuntos: colisión entre derechos fundamentales o colisión entre un derecho y u interés gubernamental. Sin embargo, también dijimos que para obtener estos frutos es indispensable que los órganos jurisdiccionales acepten de manera abierta las implicaciones de su actividad. De nada nos sirve un tribunal constitucional que use un discurso "contemporáneo" si al final de cuentas no podemos discutir sus decisiones a cabalidad.

Es posible que la mayor virtud del PP sea su capacidad para transparentar las decisiones judiciales. Desafortunadamente, en este trabajo se muestra que la Corte es muy titubeante para aceptar las implicaciones políticas de sus resoluciones y eso sólo oscurece la discusión de estos casos. Nuestra Corte ha dado un buen primer paso al dejar atrás ese discurso anquilosado de la interpretación mecánica y formalista del derecho. Está pendiente el segundo: proporcionar a los ciudadanos un producto (sus sentencias) capaz de generar la discusión pública y de fortalecer el único control posible que se puede ejercer sobre un órgano de última instancia.

\section{BIBLIOGRAFÍA}

AARNIO, AULIS, "La tesis de la única respuesta correcta y el principio regulativo del razonamiento jurídico", Doxa: cuadernos de filosofía del derecho, 8, 1990.

Ackerman, Bruce, "Beyond Carolene Products", Harvad Law Review, 98, 1985.

AleiniKoff, AleXANDER, "Constitutional Law in the Age of Balancing”,

105 Zaldívar Lelo de Larrea, Arturo, “¿Por qué analizar los fallos?”, El Universal, 13 de junio de 2008 (consulta 10 de febrero de 2011), formato html, disponible en http:// arturozaldivar.com.mx/wp-content/uploads/_Por-qué-criticar-los-fallos-Periódico-ElUniversal-Justicia-a-Debate-13-de-junio-de-2008.PDF. 
Yale Law Journal, 96, 1986-1987.

AleXy, RoBert, "Constitutional Rights, Balancing and Rationality", ¿Ratio Iuris, 16, 2003. El concepto y la validez del derecho, Barcelona, Gedisa, 2004. , Teoría de los derechos fundamentales, trad. de Carlos Bernal Pulido, Madrid, Centro de Estudios Políticos y Constitucionales, 2008. y BULYGIN, Eugenio, La pretensión de corrección del derecho: la polémica Alexy/Bulygin sobre la relación entre derecho y moral, Bogotá, Universidad Externado de Colombia, 2001.

ArteagA, Elisur, Derecho constitucional, México, Oxford, 1999.

BERLIN, Isaiah, "The Romantic Revolution: A Crisis in the History of Modern Thought", The Sense of Reality, Nueva York, Farrar, Straus and Giroux, 1998.

BERNAL PUlIDO, Carlos, El principio de proporcionalidad y los derechos fundamentales: el principio de proporcionalidad como criterio para determinar el contenido de los derechos fundamentales vinculantes para el legislador, Madrid, CEPC, 2007.

- "La ponderación como procedimiento para interpretar los derechos fundamentales", en CÁCERES, E. et al. (eds.), Problemas contemporáneos de la filosofía del derecho, México, UNAM, 2005.

BISCARETTI DI RUFFIA, Paolo, Introducción al derecho constitucional comparado, trad. de Héctor Fix-Zamudio, México, FCE, 2006.

CARPIZO, Jorge, Estudios constitucionales, México, Porrúa, 1999

Carbonell, Miguel (ed.), Neoconstitucionalismo, Madrid, 2003. , (ed.), Derecho constitucional. Memoria del Congreso Internacional de Culturas y Sistemas Jurídicos Comparados, México, UNAM, 2004. CASTRO, Juventino, El artículo 105 constitucional, México, Porrúa, 2004. ConesA, Luisa, The Tropicalization of Proportionality Balancing: The Colombian and Mexican Examples), Cornell Law School Inter-University Graduate Students Conference Papers.

CORZO, Edgar y VEGA, Juan (eds.), Instrumentos de tutela y justicia constitucional, Memoria del VIII Congreso Iberocamericano de Derecho Constitucional, México, UNAM, 2002.

Cossío, José Ramón, La teoría constitucional de la Suprema Corte de Justicia, México, Fontamara, 2002.

De Vergottini, Giuseppe, Derecho constitucional comparado, trad. de Claudia Herrera, México, UNAM, 2004. 
Dworkin, Ronald, Law's Empire, Cambridge, Harvard University Press, 1986. 2001. Taking Rights Seriously, Cambridge, Harvard University Press,

ESCAlANTE GonZAlbo, Fernando, Una idea de las ciencias sociales, México, Paidós, 1999.

FERRER MAC-GREGOR, Eduardo (coord.), Derecho procesal constitucional, México, 2002.

—_, Interpretación constitucional (3 ts.), México, Porrúa, 2005.

Fioravanti, Maurizio, Constitución. De la antigüedad a nuestros días, trad. de Manuel Martínez Neira, Madrid, Trotta, 2007.

(ed.), El Estado moderno en Europa, trad. de Manuel Martínez Neira, Madrid, Trotta, 2004.

Fiss, Owen, La ironía de la libertad de expresión, Barcelona, Gedisa, 1999.

FIX-ZAMUdio, Héctor y FERRER MAC-GREGOR, Eduardo, Las sentencias de los tribunales constitucionales, México, Porrúa-UNAM, 2009.

FiX-ZAmudio, Héctor y VAlencia CARMona, Salvador, Derecho constitucional mexicano y comparado, México, Porrúa, 2001.

GUIBOURG, Ricardo, “Alexy y su fórmula del peso”, en BEADA, Gustavo y ClÉRICO, Laura (eds.), Desafios a la ponderación, Bogotá, Universidad Externado de Colombia, 2011.

HÄBERLE, Peter, El Estado constitucional, trad. de Héctor Fix-Fierro, México, UNAM, 2003.

JACKSON, Vicki, "Being proportional about proportionality", Constitutional Comments 21, 2004.

, Constitutional Engagement in a Transnational Era, Nueva York, Oxford University Press, 2010.

JACKSON, Vicki y TUSHNET, Mark, Comparative Constitutional Law, Foundation Press, 2006.

KenNEDy, Duncan, A Critique of Adjudication, Cambridge, Harvard University Press, 1998.

LUSKY, Louis, "Footnote 4 Redux: A Carolene Products Reminiscence", Columbia Law Review, 82, 1982.

OJESTO, Fernando et al. (coord.), Jueces y política, México, Porrúa, 2005. SÁNCHEZ GIL, Rubén, El principio de proporcionalidad, México, UNAM, Instituto de Investigaciones Jurídicas, 2007. 
—_ "Recepción jurisprudencial del principio de proporcionalidad en México", Cuestiones Constitucionales, 21, 2009.

SCHWABE, Jürgen (comp.), Jurisprudencia del Tribunal Constitucional Federal Alemán (extractos de las sentencias más relevantes compiladas por Jürgen Schwabe), trad. de Marcela Anzala Gil y Emilio Maus Ratz, México, Konrad Adenauer Stiftung, 2009.

SHAPIRO, Martin, Law and Politics of the Supreme Court: New Approaches in Political Jurisprudence, Londres, Free Press, 1965.

- Courts. A Comparative and Political Analysis, Chicago, The University of Chicago Press, 1992.

Stone SweEt, Alec, Governing with Judges, Oxford, Oxford University Press, 2000.

— y MATHEws, Jud, "Proportionality Balancing and Global Constitutionalism”, Columbia Journal of Transnational Law, 47, 2008.

Stone, Tushnet et al., Constitutonal Law, Nueva York, Wolters Klower, 2009.

TAMAYO Y SALMORÁN, Rolando, Introducción al estudio de la Constitución, México, Fontamara, 1998.

Tena Ramírez, Felipe, Derecho constitucional mexicano, México, Porrúa, 2000.

TuShnET, Mark, Taking Away the Constitution form the Courts, Nueva Jersey, Princeton University Press, 2000.

VÁZQUEZ, Santiago (comp.), Libertad de expresión, México, Porrúa, 2007. ZagrebelsKy, Gustavo, El derecho dúctil, trad. de Marina Gascón, Valladolid, Trotta, 1999.

ZALDívar Lelo DE LARREA, Arturo, “¿Por qué analizar los fallos?”, El Universal, 13 de junio de 2008.

Fecha de recepción: 31 de marzo de 2011.

Fecha de dictamen: 8 de junio de 2011. 